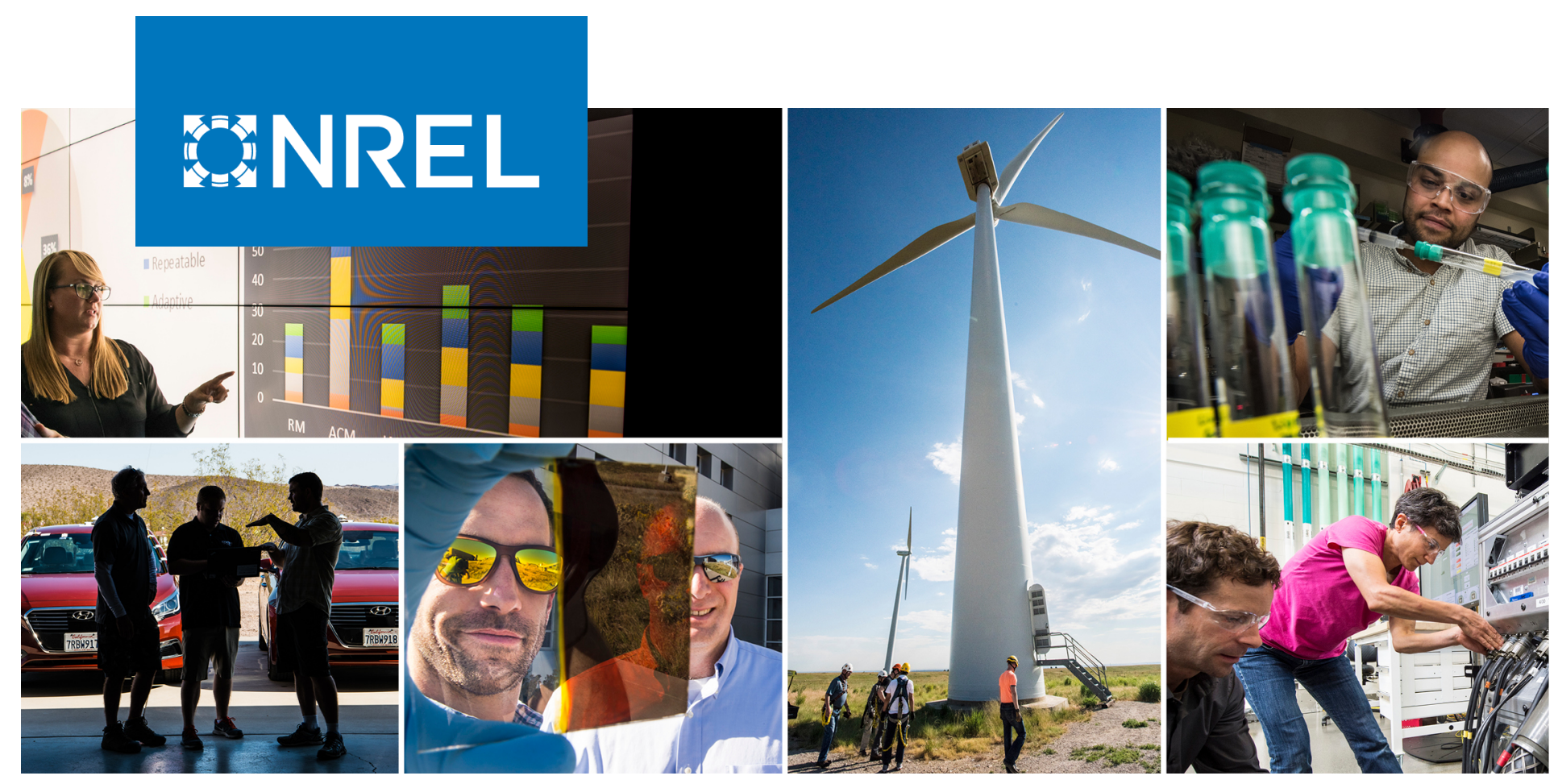

\title{
Proceedings from the State of the Science and Technology for Minimizing Impacts to Bats from Wind Energy
}

Cris Hein and Bethany Straw

National Renewable Energy Laboratory

NREL is a national laboratory of the U.S. Department of Energy Office of Energy Efficiency \& Renewable Energy

Operated by the Alliance for Sustainable Energy, LLC

This report is available at no cost from the National Renewable Energy Laboratory (NREL) at www.nrel.gov/publications.
Technical Report

NREL/TP-5000-78557

March 2021 


\title{
ENREL
}

\section{Proceedings from the State of the Science and Technology for Minimizing Impacts to Bats from Wind Energy}

\author{
Cris Hein and Bethany Straw
}

National Renewable Energy Laboratory

\section{Suggested Citation}

Hein, Cris, and Bethany Straw. 2021. Proceedings from the State of the Science and Technology for Minimizing Impacts to Bats from Wind Energy. Golden, CO: National Renewable Energy Laboratory. NREL/TP-5000-78557.

https://www.nrel.gov/docs/fy21osti/78975.pdf.

NREL is a national laboratory of the U.S. Department of Energy Office of Energy Efficiency \& Renewable Energy Operated by the Alliance for Sustainable Energy, LLC

This report is available at no cost from the National Renewable Energy Laboratory (NREL) at www.nrel.gov/publications.

Contract No. DE-AC36-08GO28308
Technical Report NREL/TP-5000-78557 March 2021

National Renewable Energy Laboratory 15013 Denver West Parkway Golden, CO 80401 303-275-3000 • www.nrel.gov 


\section{NOTICE}

This work was authored in part by the National Renewable Energy Laboratory, operated by Alliance for Sustainable Energy, LLC, for the U.S. Department of Energy (DOE) under Contract No. DE-AC36-08GO28308. Funding provided by the U.S. Department of Energy Office of Energy Efficiency and Renewable Energy Wind Energy Technologies Office. The views expressed herein do not necessarily represent the views of the DOE or the U.S. Government.

This report is available at no cost from the National Renewable Energy Laboratory (NREL) at www.nrel.gov/publications.

U.S. Department of Energy (DOE) reports produced after 1991 and a growing number of pre-1991 documents are available free via www.OSTI.gov.

Cover Photos by Dennis Schroeder: (clockwise, left to right) NREL 51934, NREL 45897, NREL 42160, NREL 45891, NREL 48097, NREL 46526.

NREL prints on paper that contains recycled content. 


\section{Acknowledgments}

This report includes contributions by presenters and panelists at the State of the Science and Technology for Minimizing Impacts to Bats from Wind Energy workshop held November 13 and 14, 2019. We thank the presenters and workshop attendees for their participation and contributions. We thank P. Field and S. Horii from the Consensus Building Institute for their planning and facilitation and for documenting content covered during the workshop as reflected in the appendices of this document. At the National Renewable Energy Laboratory, we thank E. DeGeorge, K. Sinclair, S. Rooney, B. Thresher, and C. Edgley for their support and coordination. We also thank J. Anderson, J. Brown-Saracino, C. Calabrese, A. Hale M. Speerschneider, R. Tisch and 3 anonymous reviewers for their insightful comments. Funding for the workshop and report was provided by the U.S. Department of Energy Wind Energy Technologies Office. 


\section{List of Acronyms}

$\begin{array}{ll}\text { AEP } & \text { annual energy production } \\ \text { AI } & \text { artificial intelligence } \\ \text { ATOM } & \text { Acoustic and Thermographic Offshore Monitoring } \\ \text { AWEA } & \text { American Wind Energy Association } \\ \text { BWEC } & \text { Bats and Wind Energy Cooperative } \\ \text { CBI } & \text { Consensus Building Institute } \\ \text { dB } & \text { decibels } \\ \text { DOE } & \text { U.S. Department of Energy } \\ \text { GE } & \text { General Electric } \\ \text { kHz } & \text { kilohertz } \\ \text { NREL } & \text { National Renewable Energy Laboratory } \\ \text { OEM } & \text { original equipment manufacturer } \\ \text { R\&D } & \text { research and development } \\ \text { SCADA } & \text { supervisory control and data acquisition } \\ \text { SGRE } & \text { Siemens Gamesa Renewable Energy } \\ \text { SPL } & \text { sound pressure level } \\ \text { TMIR } & \text { Turbine Integrated Mortality Reduction } \\ \text { TRL } & \text { technology readiness level } \\ \text { USFWS } & \text { U.S. Fish and Wildlife Service } \\ \text { USGS } & \text { U.S. Geological Survey } \\ \text { UV } & \text { ultraviolet } \\ \text { WETO } & \text { Wind Energy Technologies Office } \\ \end{array}$




\section{Executive Summary}

The U.S. Department of Energy Wind Energy Technologies Office, and the National Renewable Energy Laboratory convened a workshop entitled the State of the Science and Technology for Minimizing Impacts to Bats from Wind Energy on Nov. 13-14, 2019.

The objectives of the workshop were to:

- Identify the current impact minimization measures that are, or can be, used to reduce bat fatalities at wind energy facilities

- Assess the current effectiveness of those minimization measures

- Identify and assess the research and development opportunities needed to optimize and improve the effectiveness of current minimization and deterrent technologies and inform the development of future solutions

- Identify potential emerging or novel methods for informing impact minimization measures at or around wind energy facilities.

Specifically, the workshop focused on deterrent and curtailment strategies. For deterrents, the discussion centered on the existing technology (e.g., ultrasonic deterrents, dim ultraviolet light, and texture coating), integration with wind turbines (either retrofitting or out of the box installation), effectiveness, validation studies, and cost (e.g., technology, installation, validation, and maintenance). For curtailment, the conversation was divided into blanket curtailment (i.e., based on time and wind speed) and smart curtailment (i.e., blanket curtailment plus additional variables such as temperature or bat activity).

The workshop included plenary presentations, panels, and breakout sessions to share data and stakeholder perspectives and engage participants. Although there are several priority topics related to bats and wind energy, this workshop focused the discussion on the current technologies and strategies that are, or can be, used to reduce bat fatalities at wind energy facilities, status of research and development of minimization measures, opportunities to optimize costs and improve effectiveness, and potential emerging or novel approaches to explore. This workshop took a holistic approach and discussed all aspects associated with advancing deterrent technologies and curtailment strategies, including the technological, biological, economic, and regulatory barriers faced by the wind energy and wildlife community.

\section{Deterrents}

The intent of deterrents is to reduce interactions between bats and wind turbines by ensonifying the surrounding airspace with an uncomfortable or disorienting stimulus (e.g., ultrasound), or altering the appearance of the wind turbine (e.g., dim ultraviolet light or texture coating). Given that deterrents allow wind turbines to operate normally, they also may be more cost-effective than curtailment (see below), particularly in regions with a relatively long period of risk or at facilities sited in low-wind regimes. Nevertheless, several unknowns regarding deterrents remain, including long-term durability, whether bats may become habituated to visual or auditory stimuli, what sound pressure level is required to deter bats using acoustic deterrents, if there are species-specific responses to deterrent stimuli, and adaptability of the deterrents to 
evolving turbine technology. Some of the cost, technology, regulatory, and validation considerations associated with assessing the effectiveness of deterrent technology include:

- The variety of deterrent technologies and their state of readiness. Nacelle-mounted ultrasonic deterrents have advanced to commercialization, but their efficacy is limited by the rapid attenuation of high-frequency sound and therefore cannot cover the entire rotorswept zone of the current fleet of commercial wind turbines. Blade-mounted ultrasonic deterrents and other technologies (e.g., dim ultraviolet light and texture coating) are still in the early- to mid-phases of development and require further validation to demonstrate their effectiveness.

- The regulatory uncertainty. Risk of potential take of a state or federally listed species and lack of incentives may factor into decisions to host experimental studies for new technologies. Permitting requirements also may inhibit or delay studies.

- The advancement of technologies through the technology readiness level hierarchy. Research and development requires a systematic approach and allows vendors to identify failure points and system weaknesses early, in safe and low risk settings. However, it can take years to move a technology through the hierarchy.

- The expensive nature of validation studies. In addition to the cost of mortality and/or behavioral monitoring, operations staff time to support studies, clearing and maintaining research plots, hardware and software associated with the technology, and maintenance of equipment should be factored into budget planning.

\section{Curtailment}

Although deterrents rely on a behavioral response from bats to reduce interactions with turbines, curtailment alters turbine operations in response to risk factors (e.g., temporal, weather, or evidence of bat activity). Early studies observed that bats are more active during lower wind speeds and incidence of fatality was noted to be highest during late summer and early fall. These data indicated a relatively narrow window of risk based on wind speed, time of year, and time of day (i.e., night) and the potential to reduce risk by altering turbine operations (i.e., feathering turbine blades and raising cut-in speeds). This practice is commonly referred to as standard or blanket curtailment (aka operational minimization).

Blanket curtailment has shown significant reductions in fatalities, but it also reduces annual energy production and revenue, which could hinder the financial viability of wind farms in low wind class areas. Moreover, it is a relatively coarse approach that results in curtailment during times when bats may not be at risk. Smart curtailment strategies build on the foundation of blanket curtailment by incorporating additional weather variables or bat activity data as triggers for altering wind turbine operations. This approach is currently being evaluated for its ability to achieve the same level of minimization while reducing loss of annual energy production and revenue. As with deterrent technologies, it is necessary to consider the cost, technology, and regulatory and validation factors associated with assessing the effectiveness of curtailment strategies, some of which include:

- The expensive nature of validation studies. Similar to deterrent studies, validating curtailment strategies is expensive. The costs can include operations staff support for hosting studies, clearing and maintenance of research plots, mortality and behavioral 
monitoring to verify efficacy, installation and maintenance of hardware (e.g., acoustic detectors), updating supervisory control and data acquisition systems, and revenue loss associated with altered turbine operations.

- The variety of turbine hardware and software. Variation in turbine models and the wind regimes in which they are deployed influence both the cost and the feasibility of adopting curtailment. Currently, turbine models spanning more than 3 decades exist and are installed with varying supervisory control and data acquisition system capabilities. In some cases, this may limit the practicality of implementing more complex curtailment scenarios at some wind energy facilities.

- The regulatory uncertainty. Risk of mortality of threatened or endangered species factor into decisions to host experimental studies for new curtailment strategies. Permitting requirements also may inhibit or delay studies.

\section{Communication}

Communication is essential for large-scale, complex studies, and should begin early and be continuous throughout the project. The phrase "it takes a village" applies to these efforts as active participation by a diverse set of stakeholders is necessary for the project to be successful. Representatives from the technology provider, original equipment manufacturers, wind energy facility (e.g., permit managers, electrical engineers, mechanical engineers, supervisory control and data acquisition operators, and site managers), research team (e.g., field crew and statistician) make up the core group. A dedicated project manager is recommended to coordinate activities among all team members. It also is important to engage early with those outside the core project team, such as state and federal regulators.

Engaging in multistakeholder collaboratives (e.g., Bats and Wind Energy Cooperative and American Wind Wildlife Institute) can help facilitate sharing perspectives, building relationships, and discussing priorities. Networking activities such as workshops are necessary to disseminate study results and lessons learned as well as to address misperceptions. There also is an urgency to disseminate research findings more rapidly to keep pace with technology development.

\section{Study Design and Monitoring Tools}

A robust experimental design is crucial to avoid situations where inconclusive results are the product of the design rather than the strategy being tested. Experimental studies are designed to maximize detection of a treatment effect, as opposed to monitoring studies, which optimize detections of carcasses. In the early stages of planning, researchers need to articulate the objectives, clearly define the experimental units (e.g., site, turbine, night), response variable (e.g., total mortality by night or over a longer period), and sources of variation (e.g., detection probability affected by treatment). Another early step is to conduct a power analysis to determine whether the experimental design has the power to detect the desired effect. Commonly used experimental designs include a randomized block design or a completely randomized design. Each option has its advantages and disadvantages and the decision about which to choose must be weighed with other factors of the study.

The technologies and methodologies used for monitoring, such as acoustic detectors, thermal video cameras, radar, radio tags, and mortality monitoring, offer different benefits and can 
enhance our understanding of bat/wind turbine interactions. Nonetheless, it is important to understand the costs, limitations, and biases associated with each. The selection of technologies and methodologies used will depend on the study objectives, although, combining $\geq 2$ tools (e.g., mortality monitoring and thermal cameras) may provide a more complete assessment of the strategy being tested.

\section{Integration}

For bats, minimization measures are primarily enacted during the operational phase, after the facility is constructed and generating electricity. Adopting minimization measures for long-term success requires integration with wind energy infrastructure, communication, and supervisory control and data acquisition systems. Key considerations for integrating technologies include location, potential structural changes necessary to affix the technology to the wind turbine, and data security. Operators must also consider aspects of the technology, such as maintenance, power requirements, monitoring, and regulatory requirements.

Greater collaboration across the supply chain will facilitate the integration of technologies with wind turbines. For example, when technology vendors work directly with original equipment manufacturers, the two parties can coordinate the seamless integration of wind turbines and aftermarket minimization technologies. These collaborations inform technology developers about potential constraints or opportunities for potential placement locations, power availability, and communication capabilities, and give original equipment manufacturers an opportunity to optimize future turbine designs for integrating monitoring or minimization technologies (e.g., providing dedicated space for equipment). They also allow for discussion of potential warranty concerns about installing new technology on a wind turbine or changing turbine operations. Improving communication and advancing partnerships across the supply chain and throughout the phases of research and development will further streamline the integration of wildlife impact minimization technologies. This requires increasing and accelerating information dissemination to current and new audiences and sharing lessons learned.

\section{Behavior and Physiology}

It is unclear why bats approach and interact with wind turbines. Certain species appear to be attracted to these structures, but the behavioral or physiological drivers remain unknown. These potential attractants likely vary by species and habitat conditions, and may not be mutually exclusive (i.e., it could be more than one attractant). Understanding how bats perceive wind turbines may help improve minimization measures. For deterrents, improving existing or developing new technology hinges on a better understanding of the species-specific responses to various stimuli. For curtailment, knowing the behavior and physiological drivers associated with bat activity may provide opportunities to optimize curtailment strategies.

\section{Cost and Funding}

Understanding project logistics and costs is critical to the success of a project but may not be fully understood by those who have not been involved in these large-scale studies. It is important to recognize and plan for the time and labor required. Given how expensive the experimental studies are, diverse funding mechanisms are needed to reduce cost barriers. Pooling funding opportunities is advantageous for large-scale projects so that no single entity bears all the financial burden. This has been successful in recent funding opportunity announcements by the 
U.S. Department of Energy Wind Energy Technologies Office, where government funding is combined with cost-share from project team members. Another recent funding mechanism is the Wind Wildlife Research Fund, which brings a multitude of industry partners together to collectively fund priority research.

\section{Recommendations for Minimization Research}

One of the workshop outcomes was to compare minimization priorities established by the Bats and Wind Energy Cooperative during the $5^{\text {th }}$ Science Meeting in June 2018 with those of the November 2019 workshop. The Bats and Wind Energy Cooperative committee meets every 3 to 4 years to discuss the state of the science on a broad suite of bat and wind issues and to revise priorities. Using the 2018 Bats and Wind Energy Cooperative priorities for minimization strategies as a foundation, the workshop participants reiterated their relevancy and importance and voiced the need for additional priorities going forward.

To successfully advance deterrent technologies, stakeholders need to address major barriers (most notably species-specific efficacy), high costs of research and development, and lack of regulatory incentives to test new technologies. For curtailment, it is necessary to balance the conservation goals with renewable energy production. In addition, smart curtailment offers promising applications in certain situations, but continued studies on improving blanket curtailment to address remaining data gaps (e.g., fatality reduction at lower cut-in speeds, true cost of the lost energy production, contracting issues between the facility owner-operator and the offtaker who contracted for the energy to be produced, etc.) is warranted. 


\section{Table of Contents}

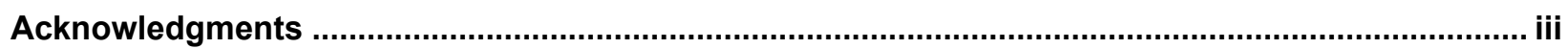





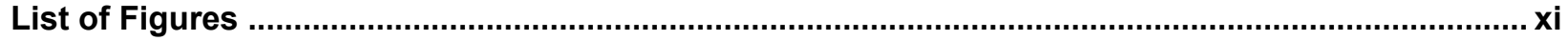

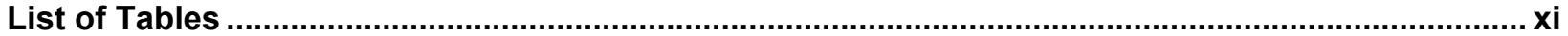

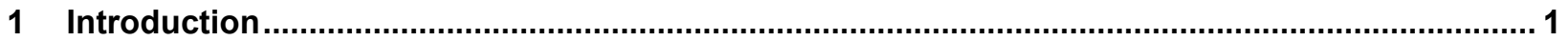

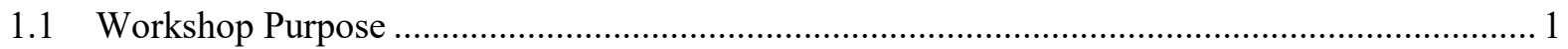

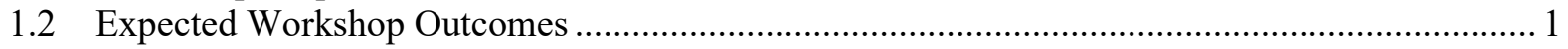

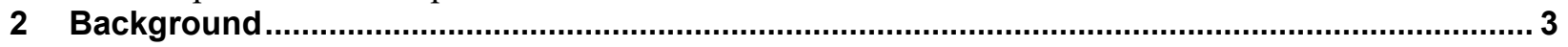

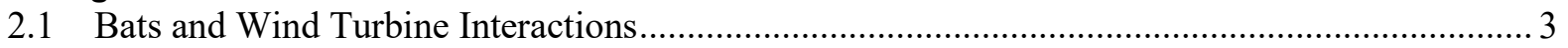

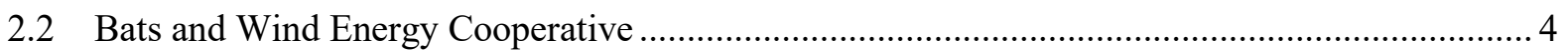

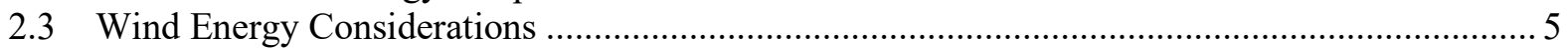

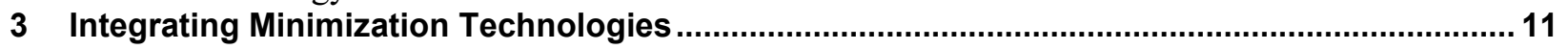

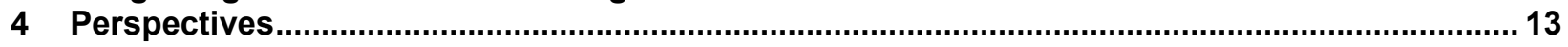

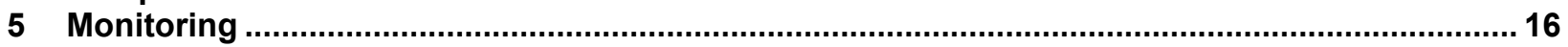

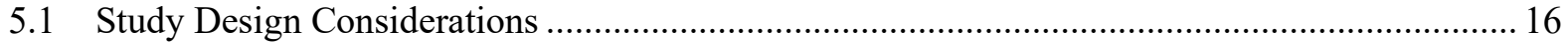

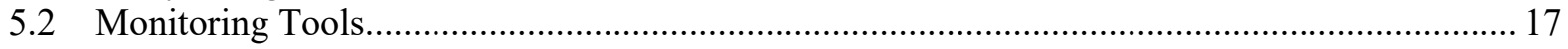







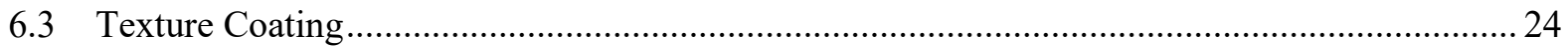

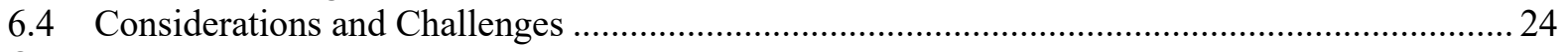

7 Curtailment

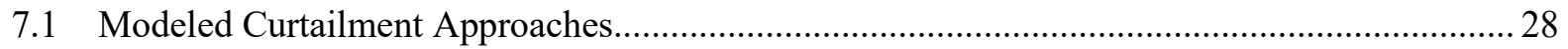

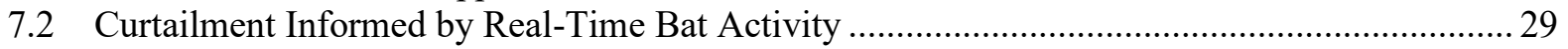

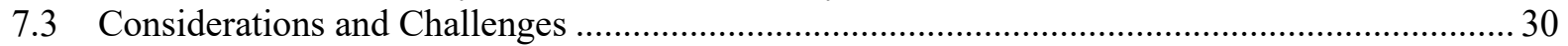









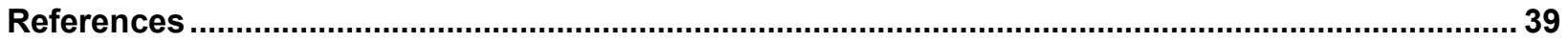

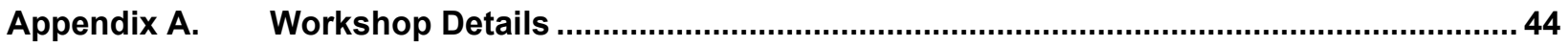

Appendix B. Deterrent Breakout Groups and Facilitated Discussion ......................................51

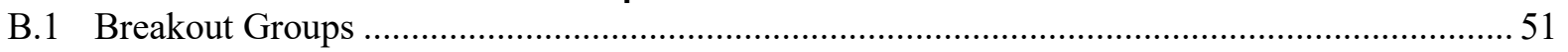

B.2 Validating Deterrent Technologies Discussion Group ......................................................... 57

Appendix C. Curtailment Breakout Groups and Facilitated Discussion ..................................... 59

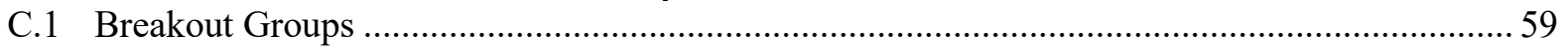

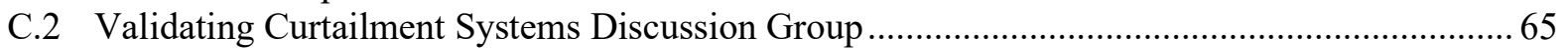




\section{List of Figures}

Figure 1. Diversity of future wind energy deployment scenarios as represented in the 2019 Standard Scenarios Report: A U.S. Electricity Sector Outlook (Cole et al. 2019). The mid-case scenario is represented by the blue dashed line with each of the orange lines representing possible future scenarios as represented in Cole et al. (2019). The shaded area represents the full range of estimated potential future scenarios.

Figure 2. The most recent onshore turbines are roughly nine times the size of pre-1990 models .............. 7 Figure 3. Annual average wind speed at $160 \mathrm{~m}$ above surface level (Draxl et al. 2015). As wind energy technology evolves, wind energy may move into lower wind speed areas.............................. 8

Figure 4. Species ranges relative to current wind energy development for the four North American species most often found at wind energy facilities. The blue shading represents species range while the black markings reflect current wind installations as recorded in the U.S. Wind Turbine Database. Image by Billy Roberts, NREL.

Figure 5. Species ranges relative to current wind energy development for four species listed as threatened and endangered in the United States. The blue shading represents species range while the black markings reflect current wind installations as recorded in the U.S. Wind Turbine Database. Image by Billy Roberts, NREL

Figure 6. Subset of considerations for the responsible deployment of wind energy. The overlap as represented in this diagram is arbitrary and does not reflect the potential intersection of these three considerations

Figure 7. Sound pressure level of ultrasound produced at 20,30,40, and $50 \mathrm{kHz}$ between 0 and $100 \mathrm{~m}$ based on a starting sound pressure level of $120 \mathrm{~dB}$ measured at $1 \mathrm{~m}$. Calculations incorporate spreading loss (dotted blue line) due to distance and mean attenuation coefficients based on hourly temperature, relative humidity, and pressure acquired from a meteorological tower at the Los Vientos Wind Energy Facility in Starr County, Texas, USA. The red dashed line represents the presumed sound pressure level $(55 \mathrm{~dB})$ necessary to deter bats. The turbine blade length of the Vestas V-110, 2-MW turbines is included for reference. From Weaver et al. 2020 ...

\section{List of Tables}

Table 1. Priorities for Reducing Bat Fatalities at Wind Energy Facilities Established by the Bats and Wind Energy Cooperative at the 5th Science Meeting, June 2018.

Table 2. Advantages and Disadvantages of Two Commonly Used Experimental Designs for Validating Impact Reduction Strategies at Wind Energy Facilities...

Table 3. Deterrent priorities established by the Bats and Wind Energy Cooperative at the $5^{\text {th }}$ Science meeting in June 2018 plus new objectives introduced at the State of the Science and Technology for Minimizing Impacts to Bats from Wind Energy, Nov. 13-14, 2019 35

Table 4. Operational Minimization and Smart Curtailment priorities established by the Bats and Wind Energy Cooperative at the $5^{\text {th }}$ Science meeting in June 2018 plus new objectives introduced at the State of the Science and Technology for Minimizing Impacts to Bats from Wind

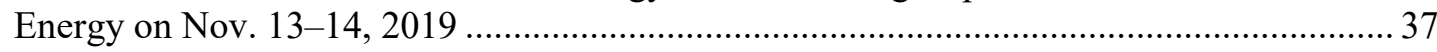

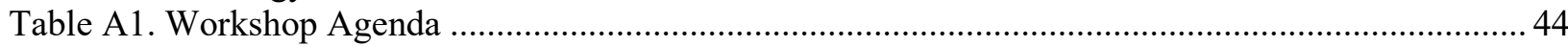



Table B1. Behavioral and Physiological Research Needs .............................................................. 51

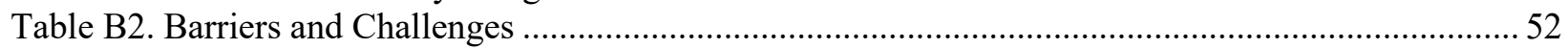

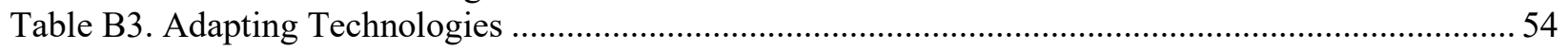

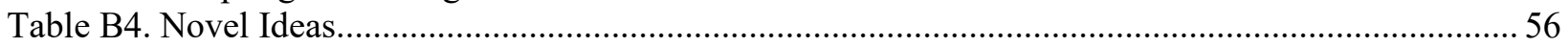

Table C1. Behavioral and Physiological Research Needs .................................................................... 59 


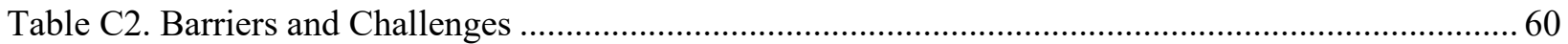

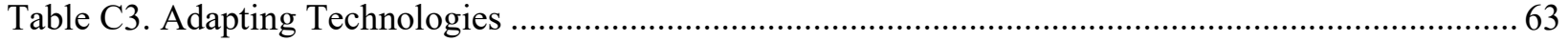






\section{Introduction}

\subsection{Workshop Purpose}

The U.S. Department of Energy (DOE) Wind Energy Technologies Office (WETO) and the National Renewable Energy Laboratory (NREL) convened a workshop entitled the State of the Science and Technology for Minimizing Impacts to Bats from Wind Energy (the workshop) on November 13-14, 2019. The workshop included plenary presentations, panels, and breakout sessions to share data and stakeholder perspectives and engage participants. Invited speakers representing a subset of private industry, academia, nongovernmental organizations, and government agencies presented research results or provided perspectives during panel sessions. The objectives of the workshop were to:

- Identify the current impact minimization measures that are, or can be, used to reduce bat fatalities at wind energy facilities

- Assess the current effectiveness of those minimization measures

- Identify and assess the research and development (R\&D) opportunities needed to optimize and improve the effectiveness of current minimization and deterrent technologies and inform the development of future solutions

- Identify potential emerging or novel methods for informing impact minimization measures at or around wind energy facilities.

Specifically, the workshop focused on deterrent and curtailment strategies. For deterrents, the discussion centered on the existing technology (e.g., ultrasonic deterrents, dim ultraviolet [UV] light, and texture coating), integration with wind turbines (either retrofitting or out of the box installation), effectiveness, validation studies, and cost (e.g., technology, installation, validation, and maintenance). For curtailment, the conversation was divided into blanket curtailment (i.e., based on time and wind speed) and smart curtailment (i.e., blanket curtailment plus additional variables such as temperature or bat activity).

Although standard pre- and post-construction fatality monitoring, potential population-level impacts of wind energy development, and other stressors impacting bats (e.g., white-nose syndrome, anthropogenic impacts, changes in insect abundance and availability) are important for understanding and resolving bat and wind energy interactions, they were beyond the scope of this workshop and were not discussed in detail.

\subsection{Expected Workshop Outcomes}

The expected outcomes of the workshop were:

- An increased understanding among a broad group of stakeholders as to the state of the science regarding current and emerging methods and technologies for minimizing wind energy impacts on bats

- Interaction and engagement among diverse stakeholders, including technology providers, operators, scientists, and government agencies 
- Identification of potential future research ideas and merge them with those developed by the Bats and Wind Energy Cooperative (BWEC; www.batsandwind.org)

- A summary that identifies the state of the science and technology for validating and implementing minimization strategies and perspectives on the key challenges and opportunities.

The following sections review the workshop topics as discussed among the participants with supporting content from publicly available webinars, reports, and peer-reviewed literature. 


\section{Background}

\subsection{Bats and Wind Turbine Interactions}

For nearly 15 years, monitoring and research studies have provided a baseline of data on the impact and patterns of bat mortality at wind energy facilities. From these, there is a general awareness of the species composition, time of year, and weather conditions associated with risk. Of the 47 bat species occurring in the United States and Canada, approximately 27, including several species from Puerto Rico, have been reported as fatalities at wind energy facilities (WEST 2019). The species adapted for open-air flight and aerial-hawking are disproportionately reported during carcass searches and include hoary bats (Lasiurus cinereus), eastern red bats ( $L$. borealis), silver-haired bats (Lasionycteris noctivagans), and Brazilian free-tailed bats (Tadarida brasiliensis). For the United States and Canada, annual mortality estimates for bats range in the 100 s of thousands, with these four species accounting for approximately $80 \%$ of fatalities (Arnett and Baerwald 2013). However, these species currently have no state or federal status. Little brown bats (Myotis lucifugus), Indiana bats (M. sodalis), northern long-eared bats ( $M$. septentrionalis), tricolored bats (Perimyotis subflavus), and Hawaiian hoary bats (Lasiurus cinereus semotus) constitute a relatively smaller proportion of reported fatalities, but are a concern because their populations are considered at risk. Several species in the latter group are listed as threatened or endangered by states and/or the U.S. Fish and Wildlife Service (USFWS), whereas others are severely impacted by white-nose syndrome.

Bat mortality at wind energy facilities across the United States and Canada show a consistent temporal pattern, with increased risk occurring between mid-July and mid-October (Arnett and Baerwald 2013). This time corresponds to when bats are staging, migrating, and mating, suggesting a behavioral or physiological component to bat and wind turbine interactions. This pattern, however, can vary by species, among years, or across latitudinal gradients, resulting in shorter or longer periods of risk. Higher mortality also corresponds to relatively low wind speed (Arnett et al. 2005). This may be associated with bat activity because it is easier to fly or insect abundance and availability may be greater during low wind speed conditions. Other weather variables, such as temperature, precipitation, and barometric pressure may also influence risk, but the magnitude of those effects remains uncertain.

Bat and wind turbine interactions may not be entirely random or coincidental events, particularly for some species. The disproportionate reporting of 4 of 47 species paired with thermal video observations of bats making multiple passes or hovering near wind turbines suggest a possible attraction (Arnett and Baerwald 2013; Cryan et al. 2014). There are several hypotheses as to why bats may approach wind energy facilities and interact with the towers, nacelle, and blades (Kunz et al. 2007; Cryan and Barclay 2009). How bats perceive wind energy facilities or wind turbines likely varies by species (e.g., tree-roosting versus cave-roosting species), landscape conditions (e.g., forested versus agricultural landscape), and turbine models (e.g., taller towers, longer blades, different ramp-up speeds); in addition, bats are likely responding to multiple cues (Hein and Hale 2019).

The existing literature regarding the behavior and physiology of bats and the observed patterns of mortality has provided us with two broad types of potential solutions: deterrents and curtailment. For example, understanding how bats use and respond to ultrasonic stimuli led to the 
investigation of acoustic deterrents. Additional work is necessary to improve this suite of technologies, while also exploring new technologies based on other sensory stimuli. Similarly, knowing the timing and conditions associated with the greatest risk has sparked research into curtailment. Given that bats are only active at night and risk is relatively high during approximately 3 months of the year with low wind speed conditions, this narrows the amount of time it is necessary to curtail wind turbines. Yet, further means of reducing the timing and conditions of curtailment are possible and can make this strategy more cost-effective.

\subsection{Bats and Wind Energy Cooperative}

BWEC was formed in 2004 and held its inaugural Science Meeting in response to reports of unexpectedly high bat fatalities at wind energy facilities. BWEC is an alliance of government agencies, private industry, academic institutions, and nongovernmental organizations that cooperate to develop and disseminate solutions to monitor and mitigate the impact of wind turbines on bats. BWEC initiated the first U.S.-based studies on curtailment and deterrents.

Every 3 to 4 years, BWEC convenes to discuss the state of the science and establish priorities to catalyze research focused on cost-effective solutions. In June 2018, BWEC held its $5^{\text {th }}$ Science Meeting and identified the following priorities (BWEC 2018):

- Population estimation, modeling, and data collection

- Fatality estimation, modeling, and sampling

- Bat behavior

- Operational minimization (or curtailment)

- Deterrent technologies.

At the time of the $5^{\text {th }}$ Science Meeting, there was little information on the effectiveness of deterrents with only one published deterrent study (Arnett et al. 2013a). Therefore, the conversations focused on:

- The spatial coverage of ultrasonic deterrents and whether bats were being pushed to the tips of the blades,

- The use of thermal video cameras to assess the behavioral response of bats to deterrent stimuli

- The potential benefit of combining two different deterrent technologies or combining deterrents with curtailment

- The degree to which deterrents can reduce bat mortality and whether it will satisfy regulators

- Additional deterrent options to explore in addition to ultrasonic deterrents (e.g., dim UV lights).

For curtailment, the discussion centered on:

- Synthesizing available information on the number of projects that are implementing curtailment

- Determining the species-specific effectiveness of different curtailment strategies

- Improving curtailment using additional variables. 
Based on the discussion, the priorities were developed to guide research for the following 3 years (Table 1).

Table 1. Priorities for Reducing Bat Fatalities at Wind Energy Facilities Established by the Bats and Wind Energy Cooperative at the 5th Science Meeting, June 2018

\begin{tabular}{|c|c|c|}
\hline Priority & Objective & Action \\
\hline \multirow[t]{5}{*}{$\begin{array}{l}\text { Deterrent } \\
\text { Technologies }\end{array}$} & $\begin{array}{l}\text { Advance deterrent } \\
\text { technologies }\end{array}$ & Conduct additional experimental studies \\
\hline & $\begin{array}{l}\text { Advance species- } \\
\text { specific knowledge }\end{array}$ & $\begin{array}{l}\text { Support species-specific assessment of the } \\
\text { effectiveness of deterrent technologies }\end{array}$ \\
\hline & $\begin{array}{l}\text { Advance } \\
\text { understanding of the } \\
\text { effective range of } \\
\text { deterrents }\end{array}$ & $\begin{array}{l}\text { Work with technology providers to provide greater } \\
\text { coverage around the wind turbines }\end{array}$ \\
\hline & $\begin{array}{l}\text { Study effectiveness } \\
\text { of combined } \\
\text { methods }\end{array}$ & $\begin{array}{l}\text { Conduct experimental studies using combined } \\
\text { approaches (e.g., curtailment and deterrents OR } \\
\text { combination of deterrents) }\end{array}$ \\
\hline & $\begin{array}{l}\text { Advance UV } \\
\text { technology }\end{array}$ & $\begin{array}{l}\text { Conduct further development and testing of UV } \\
\text { technology }\end{array}$ \\
\hline \multirow[t]{4}{*}{$\begin{array}{l}\text { Operational } \\
\text { Minimization \& Smart } \\
\text { Curtailment }\end{array}$} & $\begin{array}{l}\text { Summarize results } \\
\text { from curtailment } \\
\text { strategies }\end{array}$ & $\begin{array}{l}\text { 1) Summarize effectiveness of curtailment studies, 2) } \\
\text { assess species-specific responses to curtailment, 3) } \\
\text { quantify industry implementation of curtailment } \\
\text { strategies, and 4) identify barriers to adoption and } \\
\text { ways to increase implementation }\end{array}$ \\
\hline & $\begin{array}{l}\text { Replicate recent } \\
\text { "smart" curtailment } \\
\text { studies }\end{array}$ & $\begin{array}{l}\text { 1) Conduct "smart" curtailment studies across } \\
\text { landscapes, species, and turbine models; and 2) } \\
\text { Develop and standardize metrics and parameters for } \\
\text { reporting }\end{array}$ \\
\hline & $\begin{array}{l}\text { Verify impact of } \\
\text { feathering up to the } \\
\text { manufacturer's cut- } \\
\text { in speed }\end{array}$ & $\begin{array}{l}\text { Study effectiveness of feathering up to cut-in speed for } \\
\text { different species and turbine models }\end{array}$ \\
\hline & $\begin{array}{l}\text { Impact reduction } \\
\text { decision support tool }\end{array}$ & $\begin{array}{l}\text { Consider feasibility of a support tool to assist in } \\
\text { designing practicable curtailment strategies for different } \\
\text { scenarios }\end{array}$ \\
\hline
\end{tabular}

One outcome of this workshop was to build on the above existing BWEC priorities by discussing the progress that has been made since the $5^{\text {th }}$ Science Meeting and identifying remaining gaps.

\subsection{Wind Energy Considerations}

The wind energy industry in the United States began in earnest in the early 1980s (https://www.energy.gov/eere/wind/history-us-wind-energy) and, according to the U.S. Wind 
Turbine Database (https://eerscmap.usgs.gov/uswtdb/), has grown to 63,794 turbines in 43 states plus Guam and Puerto Rico, for a total rated capacity of 105,085 MW. Currently installed turbines range from models manufactured before 1990 to those designed today (Hoen et al. 2020). Deployment projections based on a mid-case standard scenario estimate that installed capacity from wind energy may increase to $484,000 \mathrm{MW}$ by 2050 (Cole et al. 2019). These projections are subject to a variety of factors that influence build-out and the mid-case scenario represents only one of several potential outcomes (Figure 1). ${ }^{1}$



Figure 1. Diversity of future wind energy deployment scenarios as represented in the 2019 Standard Scenarios Report: A U.S. Electricity Sector Outlook (Cole et al. 2019). The mid-case scenario is represented by the blue dashed line with each of the orange lines representing possible future scenarios as represented in Cole et al. (2019). The shaded area represents the full range of estimated potential future scenarios.

\subsubsection{Turbine Technology Trends}

Currently, the largest land-based wind turbines exceed 5.0 MW, with tip heights $>250 \mathrm{~m}$ and a rotor diameter $>150 \mathrm{~m} .^{2}$ This makes the most recent land-based turbines roughly nine times the size of those constructed 40 years ago (Figure 2). As the size of wind turbines increases, so does the capability to generate electricity at lower wind speeds (Wiser and Bolinger 2019), thus

\footnotetext{
${ }^{1}$ See the Standard Scenarios Results Viewer to explore different deployment scenarios (https://openei.org/apps/reeds/\#). To explore wind resource spatial data, see the Wind Prospector (https://maps.nrel.gov/wind-prospector) or WIND Toolkit (https://www.nrel.gov/grid/wind-toolkit.html).

2 Wind Power Monthly, August 2019; https://www.windpowermonthly.com/article/1592000/clash-titans-top-5biggest-onshore-turbines.
} 
opening new regions and markets for development, such as the southeast or southwest United States. As turbine technology evolves, so will the relationship between wind energy and bats (Figure 3, Figure 4, and Figure 5). Deployment of taller wind turbines with longer blades may require modified or alternative approaches for monitoring and minimizing impacts to bats.

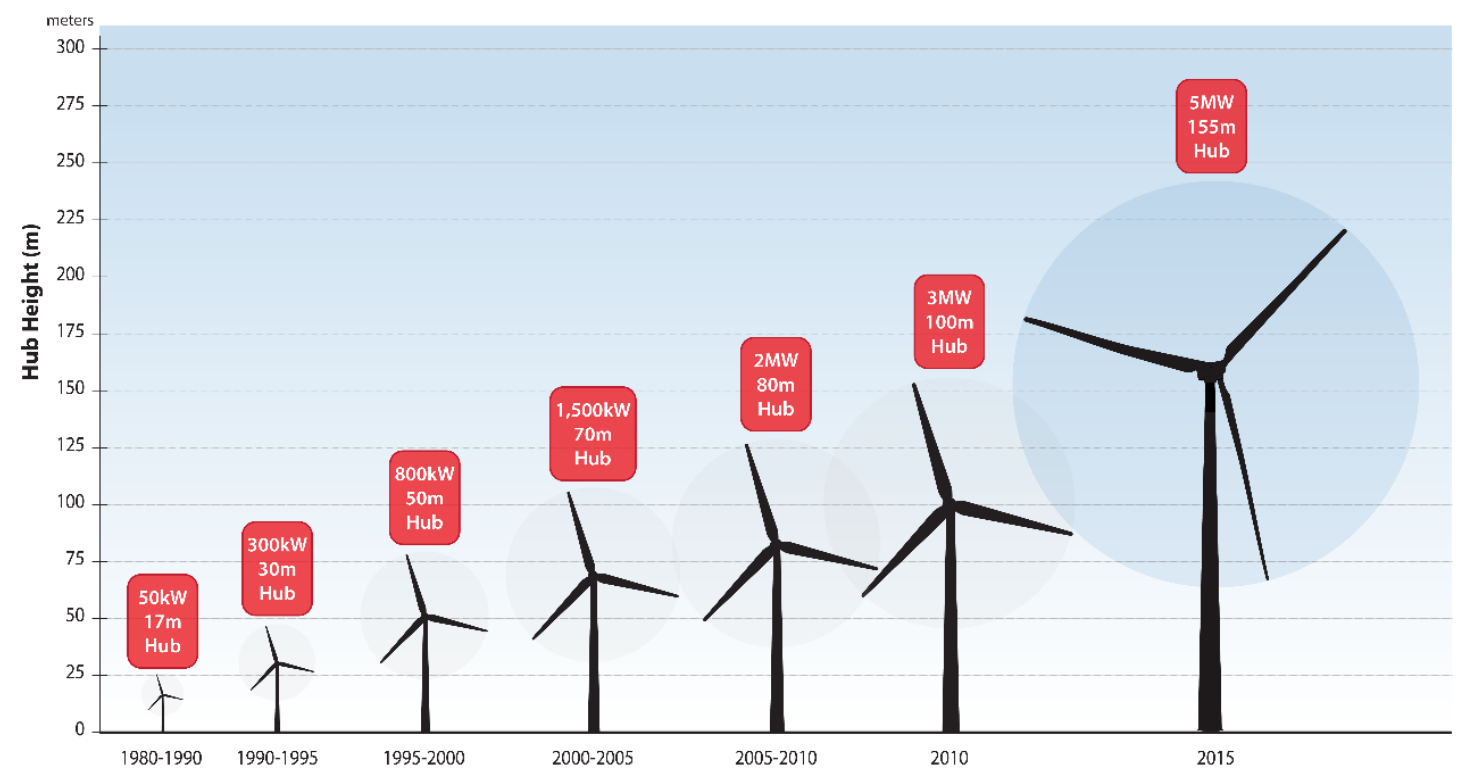

Figure 2. The most recent onshore turbines are roughly nine times the size of pre-1990 models 


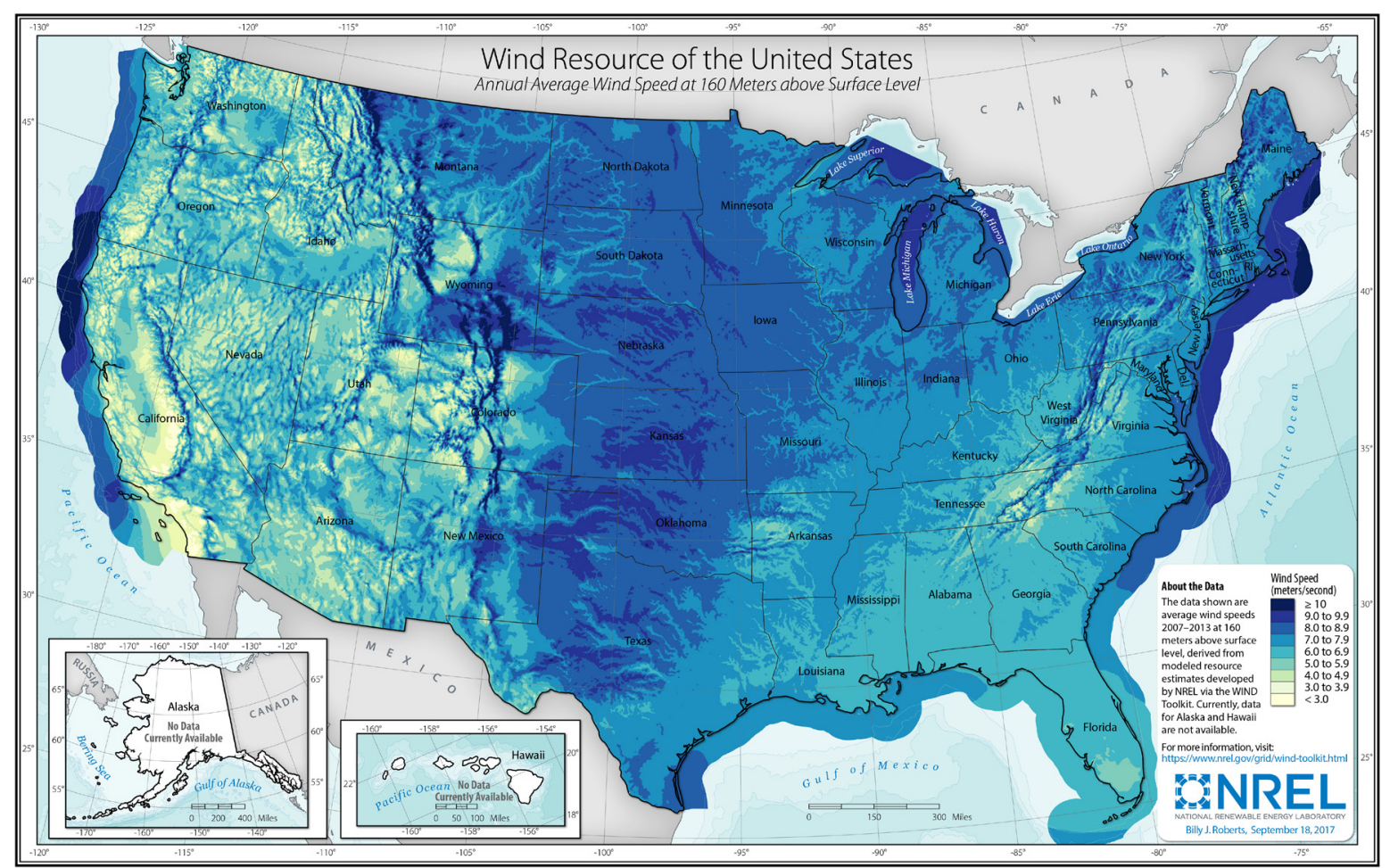

Figure 3. Annual average wind speed at $160 \mathrm{~m}$ above surface level (Draxl et al. 2015). As wind energy technology evolves, wind energy may move into lower wind speed areas. 


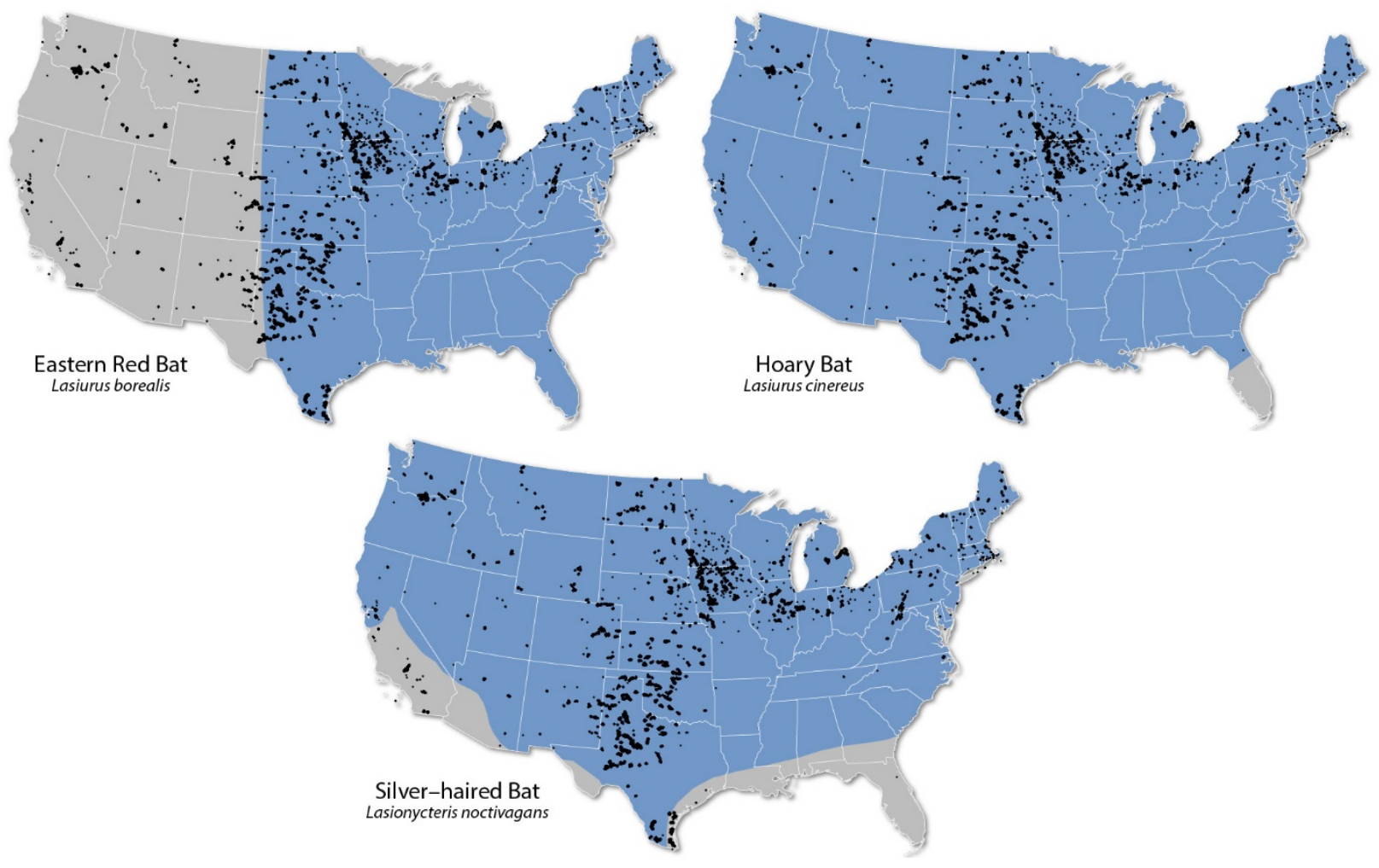

Figure 4. Species ranges relative to current wind energy development for the three North American species most often found at wind energy facilities. The blue shading represents species range while the black markings reflect current wind installations as recorded in the U.S. Wind Turbine Database. Image by Billy Roberts, NREL 

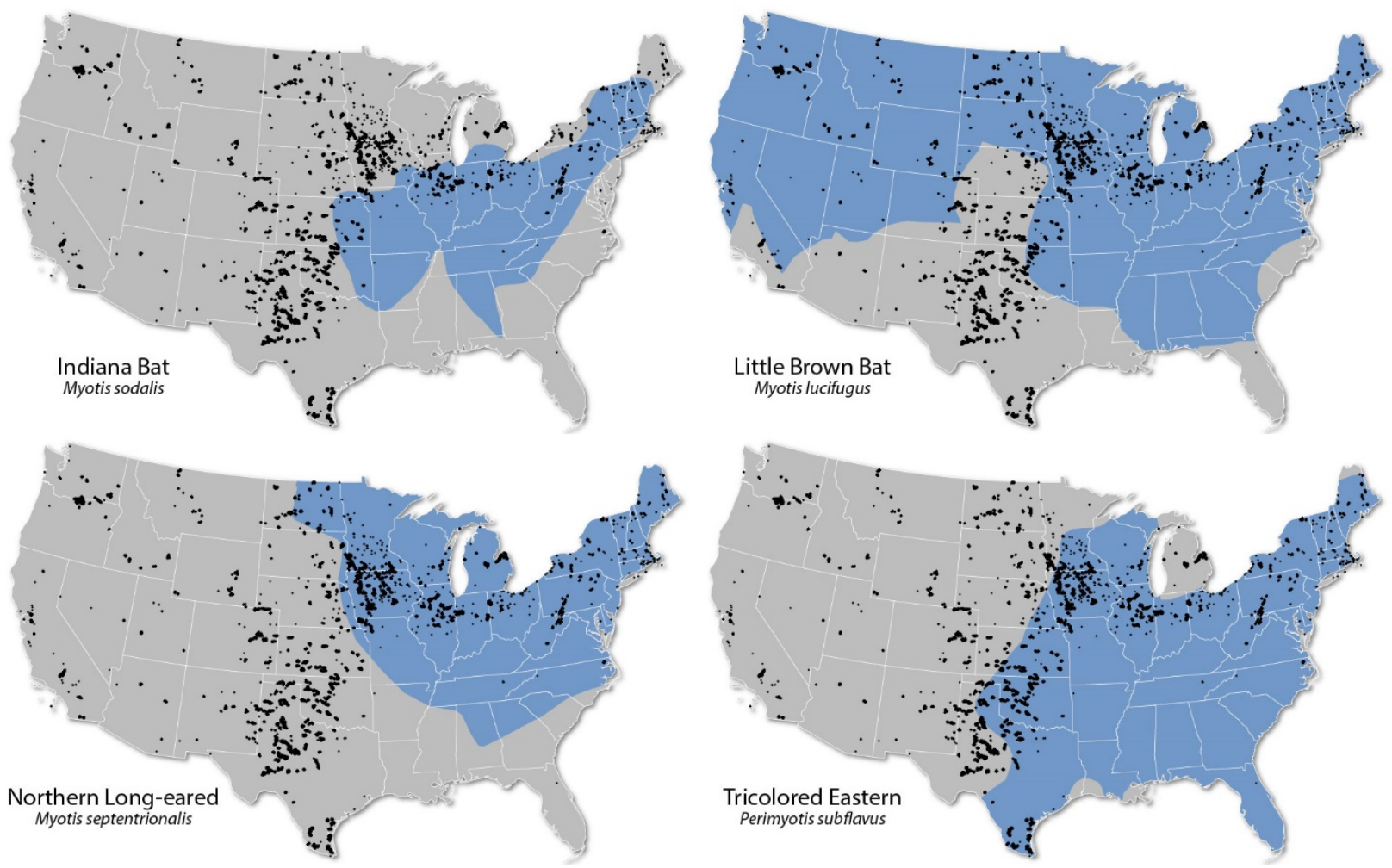

Figure 5. Species ranges relative to current wind energy development for four species listed as threatened and endangered in the United States. The blue shading represents species range while the black markings reflect current wind installations as recorded in the U.S. Wind Turbine Database. Image by Billy Roberts, NREL 


\section{Integrating Minimization Technologies}

There are opportunities to integrate technologies that minimize impacts to bats from wind energy at each stage of development (e.g., prospecting and siting, site design, construction, operation, and decommission or repowering). Quantifying the probability of the presence of and accurately estimating the risk to bats at a given location prior to construction may provide insight into siting, designing, and building wind energy facilities and their associated infrastructure in ways that can reduce impacts. However, predicting risk to bats remains a challenge because no consistent relationship has been shown between preconstruction acoustic monitoring and postconstruction mortality (Hein, Gruver, and Arnett 2013; Solick et al. 2020). Therefore, siting facilities and micrositing wind turbines are currently not proven strategies for reducing collision impacts to bats in most situations. Currently, minimization measures are only available during the operational phase, after the facility is constructed and generating electricity.

Adopting minimization measures for long-term success requires integration with wind energy infrastructure (e.g., wind turbines), technology (e.g., Supervisory Control and Data Acquisition [SCADA] systems), and operating procedures. Key considerations for integrating bat minimization technologies include system-wide resilience, grid stability, location, data security, communications standards, and potential structural changes to the infrastructure to affix the technology to the wind turbine (AWWI 2018). Operators must also consider aspects of the technology such as installation procedures, maintenance, power requirements, monitoring, and regulatory requirements (Skov Nielsen, Young, and Webster 2019).

At the workshop, participants discussed the need for collaboration throughout the supply chain. For example, when technology vendors work directly with original equipment manufacturers (OEMs), the two parties can ensure the seamless integration of wind turbines and after-market minimization technologies. This has been demonstrated through collaborations between NRG Systems and Vestas. ${ }^{3}$ Collaborations such as these make technology developers aware of potential constraints or opportunities regarding potential placement locations, power availability, and communication capabilities, and give OEMs an opportunity to optimize future turbine designs for integrating monitoring or minimization technologies (e.g., providing dedicated space for equipment). Some of these modifications are presented as options during the procurement process, such as the wildlife mode offered by Siemens Gamesa Renewable Energy (SGRE) ${ }^{4}$; or even as parallel customer fiber networks that allow after-market technologies to connect to the network without compromising security. Improved communication and advancing partnerships across the supply chain and throughout phases of development and testing will further streamline the integration of wildlife impact minimization technologies. This requires increasing and accelerating information dissemination to current and new audiences as well as sharing lessons learned.

${ }^{3}$ https://www.nrgsystems.com/news-media/vestas-partners-with-nrg-systems-to-resell-batdeterrenttechnology/\#: : text=Hinesburg $\% 2 \mathrm{C} \% 20$ Vermont $\% 2 \mathrm{C} \% 20 \mathrm{USA} \% 20 \% \mathrm{E} 2 \% 80 \% 93 \% 20 \mathrm{NRG}, \mathrm{co}$ mplete $\% 20$ with $\% 20$ installation $\% 20$ and $\% 20$ service $\% 2 \mathrm{C}$. ${ }^{4}$ https://www.siemensgamesa.com/explore/journal/uniting-environment-and-technology 
Uncertainty and the lack of clear market drivers pose a challenge to hosting validation experiments and adopting minimization strategies. The business case needs to be clearly articulated for operators taking on additional cost to purchase and maintain equipment and OEMs incorporating considerations for after-market minimization technologies into turbine designs. Moreover, the true cost of these technologies needs to be well defined. Although the capital cost may be clear, operations and maintenance expenditures and costs associated with running these technologies are not well understood. Articulating the true costs can uncover opportunities for innovation that will further encourage adoption and streamline integration of minimization technologies.

The most cost-effective options for instrumentation and technologies that support wildlife impact minimization strategies will serve more than one purpose. This includes instruments that inform turbine controls or monitor system health. Examples of novel applications that have the potential to serve both turbine operations and wildlife impact minimization needs include consensus wind resource measurement to provide more accurate readings (Annoni et al. 2019) and blade damage sensors. Further investigation into new technologies or novel applications that may offer multiple benefits will bolster the business case for such investments.

Below are additional suggestions to improve the integration of technologies:

- Host meetings that bring technology vendors, OEMs, and industry together to discuss the technical requirements (e.g., power and communication access).

- Communicate internally to familiarize the scope and benefits of validating and implementing minimization technologies with decision makers.

- Define success for each stage of development of a technology and acknowledge that less than ideal results still have value and can be improved upon.

- Accelerate the dissemination of preliminary results. Waiting until the peer-review process is completed can hinder the advancement of technology.

- Explore incentives for hosting validation studies, including expedited permits for potential take at sites within the range of endangered species. 


\section{Perspectives}

Stakeholders represent a diverse set of perspectives, but the community recognizes the need to generate renewable energy and to practicably reduce wildlife impacts. Achieving these goals requires balancing conservation of species, market competitiveness, and legal compliance (Figure 6).

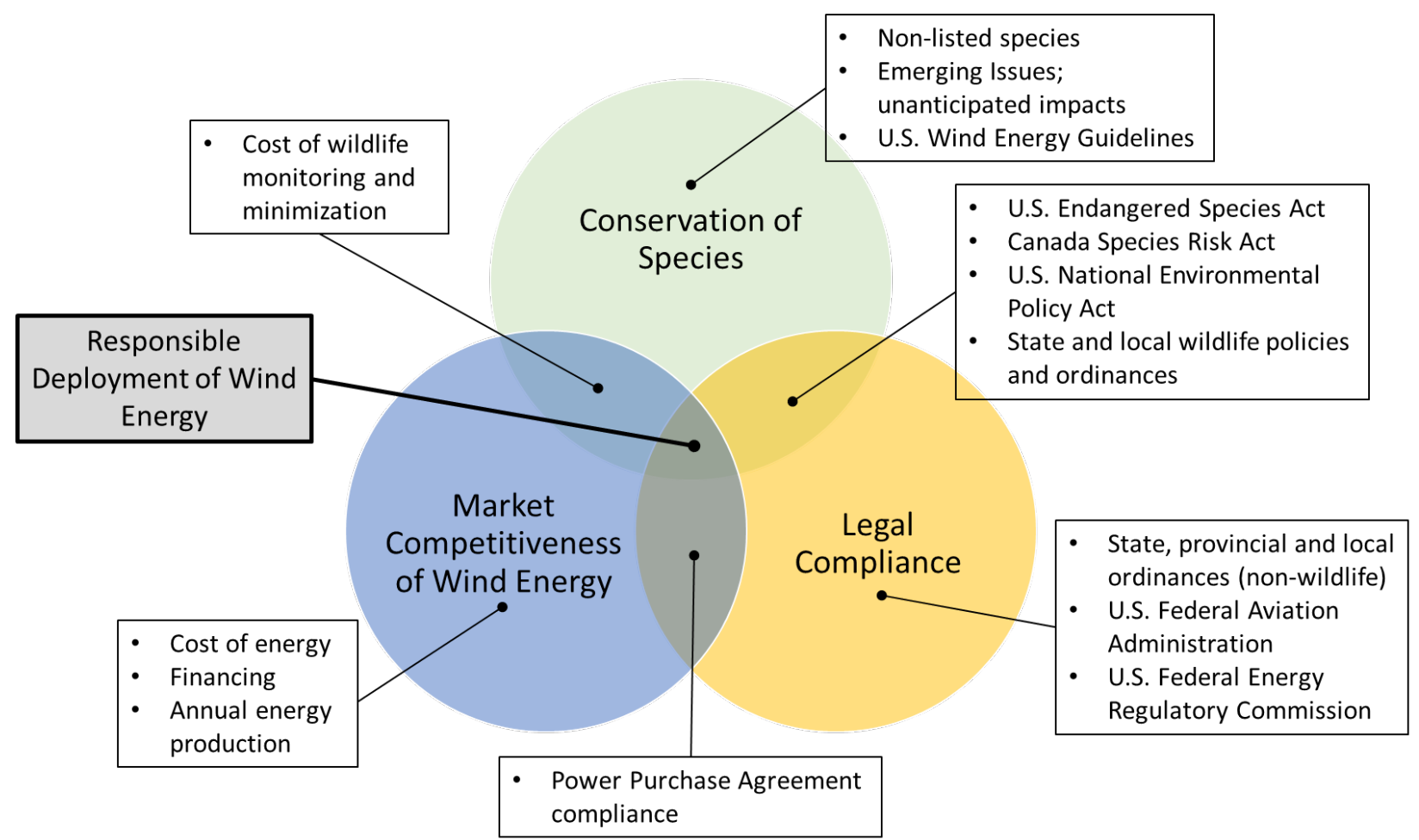

Figure 6. Subset of considerations for the responsible deployment of wind energy. The overlap as represented in this diagram is arbitrary and does not reflect the potential intersection of these three considerations.

In the United States, the primary federal statutes relevant to bats and wind energy are the National Environmental Policy Act and the Endangered Species Act. State-specific policies also apply, but regulations vary considerably. Although the National Environmental Policy Act requires an assessment of impacts and the identification of mitigation ${ }^{\mathbf{5}}$ measures, there is not a legal requirement to mitigate (42 U.S.C. $\$ 4321$ et seq. 1969). Therefore, legal requirements to minimize impacts to bats are rooted in the Endangered Species Act (16 U.S.C. $§ 1531$ et seq. 1973) or state-specific policies and ordinances. The Endangered Species Act only applies to species that have already been identified as threatened or endangered by the USFWS. In Canada, the Species at Risk Act $2002^{6}$ is the federal law identifying and recovering listed species. The

\footnotetext{
${ }^{5}$ The United States Fish and Wildlife Service defines mitigation as measures taken to "avoid, minimize, and compensate" for impacts. https://www.federalregister.gov/documents/2016/11/21/2016-27751/us-fish-and-wildlifeservice-mitigation-policy

${ }^{6}$ https://laws-lois.justice.gc.ca/eng/acts/s-15.3/
} 
Act designates the Committee on the Status of Endangered Wildlife in Canada to assess the conservation status of species for consideration by the Minister of the Environment and creates prohibitions to protect listed species and their critical habitat. Provincial-specific wildlife laws also regulate activities that impact wildlife. Because of the bats' legal status, risk tolerance by the industry for these species is relatively low, and there are existing regulatory mechanisms that guide determination of take limits and mitigation requirements.

As mentioned in the Background section, four non-listed species account for the majority of reported fatalities. Uncertainty regarding the population status and trends of these species creates challenges in determining whether the direct impact from wind turbines is sustainable. Although there is growing concern for these species, risk tolerance by the industry is often high as there is no consistent guidance for an appropriate level of mortality or mitigation.

The American Wind Energy Association and many individual companies have stated their commitment to implementing the USFWS Land-Based Wind Energy Guidelines ${ }^{7}$ which are voluntary, but when, where, and how much to minimize impacts to non-listed species remain subject to the discretion of individual wind energy facilities. This dynamic can put industry on unequal footing with respect to market competitiveness. Ultimately, all participants across the energy supply chain have an interest in providing/receiving reliable, low-cost energy. Thus, in part, energy development and operation is driven by cost and voluntary wildlife minimization does not currently contribute to a company's competitiveness in the market. Moreover, there are legal ramifications to operating facilities if power purchasing agreements are not met. As such, a company willing to implement a minimization strategy for non-listed bats may not be as competitive relative to other companies.

The choice to adopt additional minimization strategies is not solely based on costs. Currently, only curtailment meets regulatory requirements for reducing collisions with listed bats. However, stakeholders agree there is no "one-size-fits-all" approach and flexibility is needed to account for individual circumstances for each wind energy facility. A broader suite of options is needed, but regulatory agencies require confidence in the species-specific efficacy of new strategies. Testing or adopting new strategies requires post-construction monitoring to validate results and verify impacts remain within permitted levels. These studies require additional planning to develop and implement a robust study design, and the cost and level of effort associated with these studies can be relatively expensive compared to standard post-construction mortality monitoring.

Ultimately, regulators and the wind energy industry would like to see a proven, commercialized suite of tools that cost-effectively meet species-specific conservation needs. However, investments are needed to support 1) validation studies at utility scale wind energy facilities, 2) replication of efficacy studies for a variety of species and locations, 3) capital investments in commercialized solutions, 4) operations and maintenance of adopted technologies to ensure they perform as intended, and 5) monitoring to verify impacts remain within agreed upon levels (e.g., level of take permitted in an incidental take permit).

${ }^{7}$ https://www.fws.gov/ecological-services/es-library/pdfs/WEG_final.pdf 
Additional perspectives shared by workshop participants on the challenges and opportunities of validating and implementing minimization technologies include:

\section{Primary drivers and incentives for testing minimization strategies}

- Support renewable energy as a viable strategy that is commercially competitive with fossil fuels to help combat climate change impacts.

- Provide regulatory support for testing of new strategies.

- Reduce impacts on wildlife and risk of biodiversity loss.

- Proactively implement conservation strategies to prevent other species becoming listed as threatened or endangered.

- Create other solutions in addition to curtailment to allow for broader suite of options.

- Promote leaders in the industry who demonstrate responsible stewardship.

\section{Owning and sharing risk}

- Everyone should share the responsibility to ensure technology development and testing address minimization priorities and testing and implementation occur appropriately.

- Regulators aim to balance risk (ecological impacts, litigation, etc.) and management flexibility (support testing and learning given the many uncertainties).

- Risk may also serve as an opportunity to encourage industry to innovate and stay up to date with technological advancements.

- Companies may be more inclined to test new strategies where listed species occur if supported by regulators. 


\section{Monitoring}

\subsection{Study Design Considerations}

Regardless of the technology, validation studies have four things in common: they require collaboration, are expensive, have a limited window of time to collect data, and warrant a robust experimental design. First, the phrase "it takes a village" applies to these efforts as a diverse set of stakeholders are necessary for the project to be successful. Representatives from the technology provider, turbine manufacturer, wind company (e.g., asset manager, engineers, control center), and research team (e.g., field crew and statistician) make up the core group. Engaging with state and federal agencies early in the project is also recommended. Second, there are a variety of costs associated with these studies, including the technology, installation, field monitoring, and landowner payments to clear and maintain search plots as well as analysis, report writing, and review tasks. Third, timing is critical. To maximize detections (e.g., bat passes, observations, or carcasses), sampling should occur during the period of highest activity/mortality, which is often late summer and early autumn. Finally, a well-thought-out experimental design is crucial to avoid situations where inconclusive results are the product of the design rather than the technology being tested. Developing an experimental design results from the project team communication and planning, logistics and available budget, and timing.

This workshop focused on experimental designs associated with studies to assess the effectiveness of an impact reduction strategy and not mortality estimation (Sinclair and DeGeorge 2016). Experimental studies are designed to maximize detection of treatment effects (e.g., control for variation, isolate treatment effects, and support the appropriate level of inference). Although important, the workshop did not discuss standard post-construction monitoring used to estimate mortality nor monitoring for rare species (i.e., evidence of absence). These methods are often designed to optimize detection of carcasses and/or minimize costs.

In the early stages of developing the experimental design, researchers need to clearly define the experimental units (e.g., site, turbine, night), response variable (e.g., total mortality by night or over a longer period), and sources of variation (e.g., detection probability affected by treatment). Another early step is to conduct a power analysis. Considerations for a power analysis include the desired level of mortality reduction, number of turbines searched, expected mortality, variation in mortality among turbines, and search biases (e.g., searcher efficiency). A power analysis is not only helpful in determining the design, but it can also help estimate the cost of the study. The key question is to determine whether the study design has the power to detect the desired effect. If not, the options are to increase replication (and likely cost), reduce the scope (e.g., reduce the number of treatments in the study), or hold the study until additional resources are available to conduct it properly.

Two commonly used experimental designs are the randomized block design and the completely randomized design. For the same power to detect a treatment effect, randomized block design studies can require fewer turbines, but treatments must be applied to all turbines, which can increase cost and complexity. Alternatively, completely randomized design studies require more turbines, but a given treatment is only assigned to a subset of turbines for the entire study, which may simplify implementation. Selecting which design is appropriate depends on considering the advantages and disadvantages relative to logistics and budget (Table 2). 
How the data are reported is another important factor to consider when designing a study. Lack of standardization among studies makes it difficult to compare results. For example, there is no consistency in how uncertainty of the estimated effectiveness is reported. Some studies use $90 \%$ confidence intervals, while others use $95 \%$ confidence intervals. The higher the percentage, the larger the interval, but the greater the confidence in being correct. For example, with a $90 \%$ confidence interval, there is a 1 in $10(10 \%)$ chance of being wrong, compared to a 1 in 20 chance $(5 \%)$ of being wrong with a $95 \%$ confidence interval. Given the level of effort, cost, and importance of determining the effectiveness of a minimization strategy, it is more appropriate to have higher confidence in the results.

Table 2. Advantages and Disadvantages of Two Commonly Used Experimental Designs for Validating Impact Reduction Strategies at Wind Energy Facilities

\begin{tabular}{|c|c|c|}
\hline $\begin{array}{l}\text { Experimental } \\
\text { Design }\end{array}$ & Advantages & Disadvantages \\
\hline $\begin{array}{l}\text { Randomized Block } \\
\text { Design }\end{array}$ & $\begin{array}{l}\text { - } \quad \text { Controls for a large source of } \\
\text { variation (e.g., turbine to turbine) } \\
\text { - } \quad \text { Greater power to detect effect } \\
\text { - } \text { Assumes same detection rate } \\
\text { per turbine, which eliminates } \\
\text { need to conduct bias trials } \\
\text { - } \quad \text { Relatively fewer turbines }\end{array}$ & $\begin{array}{l}\text { - } \quad \text { Mortality per unit is smaller } \\
\text { - Requires treatments } \\
\text { implemented at all turbines (e.g., } \\
\text { deterrents installed on all } \\
\text { turbines) }\end{array}$ \\
\hline $\begin{array}{c}\text { Completely Randomized } \\
\text { Design }\end{array}$ & $\begin{array}{l}\text { - Mortality estimated across the } \\
\text { - } \quad \text { Turbire study } \\
\text { - } \quad \text { Relatively simple analysis } \\
\text { - Treatments implemented on a } \\
\text { subset of study turbines (e.g., } \\
\text { fewer turbines equipped with } \\
\text { deterrents) }\end{array}$ & $\begin{array}{l}\text { - Less statistical power } \\
\text { - Detection trials necessary }\end{array}$ \\
\hline
\end{tabular}

\subsection{Monitoring Tools}

The technologies and methodologies used for monitoring bat activity and mortality offer different benefits and can enhance our understanding of bat/wind turbine interactions; however, it is important to understand the costs, limitations, and biases associated with each. The project team must recognize that validating an impact reduction strategy is often more labor-intensive and expensive than standard post-construction monitoring to estimate fatality. Here we focus on how these technologies and methodologies are used to assess the effectiveness of minimization strategies. The technologies and methodologies used will depend on the study objectives and, in most cases, all are not required (Hein 2017). Combining $\geq 2$ tools may provide a more complete assessment of the strategy being tested but will increase the scope and cost of the project.

\subsubsection{Acoustic Detectors}

Acoustic detectors are relatively inexpensive and provide data on the presence of species and relative activity. They include a time stamp, which can be used to identify the time of night, 
operational status of the wind turbine (e.g., operating or is idle), and weather conditions associated with each recorded bat call. Acoustic detectors also require little power to operate and long-term data storage capabilities allow for long-term deployment. Acoustic detectors are being used to model bat activity with weather data to develop algorithms used for smart curtailment strategies (Behr et al. 2017). In addition, curtailment decisions can be based on real-time bat activity (Hayes et al. 2019).

Acoustic detectors provide a time stamp for each echolocation sequence but are not able to collect data on when collisions occur. The range of detection is relatively short and may not extend beyond $40 \mathrm{~m}$. The detection distance is also likely to vary among detector types, weather conditions, species (low frequency, high intensity calling bats may be recorded at longer distances), and the orientation of the bat (i.e., is it echolocating toward the microphone). There also are challenges with correlating echolocation sequences to species. Several software packages are available for automatic identification, but there can be misidentifications, particularly if the quality of the echolocation sequence is poor. The most vulnerable part of the detectors is the microphone. Microphones are exposed to the elements and can deteriorate over time, resulting in degraded or missed data. Weatherization approaches to protect the microphone can also distort or block echolocation sequences.

\subsubsection{Thermal Video}

Thermal video cameras can be relatively expensive (although prices are decreasing), and the cost varies with the type of technology and the associated support equipment needed. For example, near-infrared cameras require a supplemental light source. These cameras require greater power and data storage and cannot be deployed for long-term use. Like acoustic detectors, thermal cameras provide data on the timing of presence and relative activity, but they can also show where bats are interacting with wind turbines (e.g., tower, nacelle, and blades) and when risky behaviors occur. These data also can be related to weather and operational conditions. Thermal video cameras are well-suited to understand how bats are interacting with wind turbines, and they can supplement studies assessing the effectiveness of deterrent stimuli by allowing for comparison in the number of observations and types of behaviors recorded during control and treatment conditions (Cryan et al. 2014; Huzzen, Hale, and Bennett 2020).

Although the range of detection for thermal cameras is greater than acoustic detectors, they are still somewhat limited. For most modern wind turbines, it is challenging to visualize the entire rotor-swept area and differentiate bats from other targets (e.g., birds and insects). In addition, two cameras, and their precise positioning, at a wind turbine are necessary to track the bats flight path in 3-dimensional space. Currently, it is almost impossible to identify species from video observations alone. The processing and analysis of data can be labor-intensive and timeconsuming. Machine learning and artificial intelligence will help drive down costs, but applications are still in their infancy.

\subsubsection{Radar}

Radar can monitor a much larger spatial scale than acoustic detectors and thermal video cameras (Cryan et al. 2014). Data gathered from radar studies include flight height, speed, and direction; passage rates; and the timing of observations. These data can be used to determine if targets are flying within or adjacent to a wind farm and whether targets are above or below the rotor-swept area. 
Radar systems can be cost-prohibitive to purchase and/or deploy and there are some operational challenges with signal interference from wind turbines and certain topographies. Moreover, taxonomic identification is nearly impossible without tracking radar units or software packages that process wing beat patterns.

\subsubsection{Radio Transmitter and Global Positioning System Tags}

Tracking bats can provide information regarding individual variation in behavior. During the tagging process, species, sex, and age data are collected. Most studies use radio transmitters to track nightly activity patterns, short distance movement patterns, and roost locations. The Motus Wildlife Tracking System (https://motus.org/) makes it possible to establish long-term monitoring stations for radio-tagged wildlife. The Pacific Northwest National Laboratory is developing new radio transmitters that balance the size and battery life suitable for tracking bats. ${ }^{8}$ Recently, global positioning system tags have been used on hoary bats to observe multimonth, long distance movements (Weller et al. 2016). Tagged bats can provide information on habitat use and interactions with wind farms or wind turbines.

Tracking bats is time-consuming and expensive. Tracking bats long-distance with radio transmitters can even involve fixed-wing aircraft. Most global positioning system tags are too heavy for bats in North America, and those that are available require the bat or tag to be recaptured to download the data. Thus, sample sizes are often limited to a few individuals.

\subsubsection{Carcass Searches}

Currently, our best approach to determining the effectiveness of a minimization technology is to conduct carcass searches and compare mortality among control and treatment conditions. Carcasses provide data on the individual, such as species, relative age, and sex. They also offer the opportunity to take tissue samples for additional analyses (e.g., stable isotopes or genetics/genomics). Mortality data are often presented as a percent reduction rate of the treatment relative to control conditions. These data should be presented at the species level when sample size permits.

Carcass searches require extensive coordination among researchers and wind industry partners and have limitations in the data they provide. It is not possible through carcass searches to determine the time of death or the conditions under which the collision occurred. At best, it is possible to determine that a carcass died the previous night. To determine when a collision occurs requires monitoring technologies (e.g., thermal imaging, strike detectors, etc.). The additional information gained by pairing carcass searches with other technologies should be balanced by the increased cost to the study.

\footnotetext{
${ }^{8}$ https://www.nationalwind.org/new-research-on-deterrents-and-monitoring-for-bats-at-wind-energy-facilities-
} supported-by-the-u-s-department-of-energy/ 


\section{Deterrents}

Reducing the frequency and duration of interactions between bats and wind turbines may provide a practicable minimization strategy. The intent of deterrents is to reduce interactions between bats and wind turbines by ensonifying the surrounding airspace with an uncomfortable or disorienting stimulus (e.g., ultrasound) or altering the appearance of the wind turbine. Deterrents may provide a viable alternative to curtailment (see Section 7) in reducing bat fatalities for some species. Given that deterrents allow wind turbines to operate normally, they also may be more cost-effective, particularly in regions with a relatively long period of risk or at facilities sited in low-wind regimes. Nonetheless, several unknowns remain, including long-term durability, whether bats may become habituated, sound pressure level (SPL) required to deter bats, speciesspecific responses to deterrent stimuli, and adaptability to evolving turbine technology.

Current ultrasonic deterrents focus the frequency range on the characteristic frequency range of the species of interest, which for most species in the United States and Canada is approximately 20-50 kHz. Several technologies have included $>50 \mathrm{kHz}$, but these frequencies attenuate rapidly in the atmosphere and may not be worth the resources and energy to transmit. Studies investigating the effectiveness of ultrasonic deterrents began in 2006 with preliminary lab and field trials (Spanjer 2006; Szewczak and Arnett 2006; Szewczak and Arnett 2007). These ground-based studies demonstrated the potential of the technology, leading to the first field validation study at an operational wind energy facility (Arnett et al. 2013a). Deaton Engineering developed the deterrent system used in Arnett et al. (2013a) using a 4 x 4 configuration of electrostatic transducers. Despite numerous technical difficulties with the deterrent devices (e.g., water entry and overheating events), the results showed a significant reduction in overall fatalities for species using relatively low frequency echolocation $(<35 \mathrm{kHz}$; e.g., hoary bats and silver-haired bats). After the promising results by Arnett et al. (2013a), deterrents were thought to be a viable solution if the durability and performance of the devices could be improved. Since those initial studies, several advances in deterrent technology have been developed, improving their reliability. However, studies at operational wind energy facilities continue to show varying success among species. This may relate to our lack of understanding about how species respond to ultrasonic stimuli and/or how rapidly and progressively (i.e., more severe at higher frequencies) signals attenuate in the atmosphere (Lawrence and Simmons 1982).

Two nacelle-mounted deterrent technologies, developed by General Electric (GE) and NRG Systems are now commercially available, and therefore are considered to meet the requirements for a high technology readiness level (TRL). ${ }^{9}$ Blade-mounted deterrent technologies, using either passive whistle designs or piezoelectric transducers, are in development and considered to be in the low- to mid-TRL range. The advantage of installing deterrents on the blades is to increase the SPL, particularly for the higher frequency sounds, out to the tips of the blades. Regardless of the technology, additional research is critical to increase the success of ultrasonic deterrents.

Recently, the use of texture coating on turbine towers and illuminating wind turbines with dim UV light have been explored. These strategies attempt to alter bats' perception of wind turbines

${ }^{9}$ http://acqnotes.com/acqnote/tasks/technology-readiness-level 
so they do not mischaracterize the structures as a potential resource, such as a water source or roost. Studies to date on these strategies have been on a relatively small scale (e.g., a couple of operating wind turbines) and broader-scale testing is warranted.

\subsection{Ultrasonic Deterrents}

\subsubsection{Nacelle Mounted}

Since the Arnett et al. (2013a) study, two additional nacelle-mounted deterrent technologies have been tested at operational wind energy facilities and have become commercially available. GE developed one of the deterrent technologies, a pneumatic horn or nozzle that generates a broadband frequency range (30-100 kHz) using compressed air (Romano et al. 2019). The nozzles are connected to 5-horsepower compressors installed inside the wind turbine tower. Based on lab and ground-based field trials, Kinzie et al. (2018) reported the GE deterrent system was effective to $\leq 30 \mathrm{~m}$. Romano (2019) estimated that between $35 \%$ and $56 \%$ of the rotor-swept area was within the ensonified zone, depending on nozzle configuration, blade positioning, and environmental factors (e.g., relative humidity).

From 2014 to 2015, GE tested different configurations using four nozzles and a constant sound emission. ${ }^{10}$ In 2016, six nozzles were used and the study tested a pulsed sound emission. In general, Romano et al. (2019) observed differences within species among the different treatment configurations and among species within a given treatment configuration. Relatively consistent results were observed for hoary bats, with an approximate mean reduction of $30 \%$ across treatment configurations. Greater variability was observed for eastern red bats and silver-haired bats with some treatments for eastern red bats indicating a mean increase in fatality.

NRG Systems developed the other nacelle-mounted deterrent technology that has been tested at operational wind energy facilities. This technology uses a system of piezoelectric transducers, organized by frequency into six subarrays $(20,26,32,38,44,50 \mathrm{kHz}) .{ }^{11}$ The SPL of the devices, measured at $1 \mathrm{~m}$, shows an average of 122 decibels $(\mathrm{dB})$. Depending on ambient conditions, it is estimated that the intensity necessary to deter bats for a $20 \mathrm{kHz}$ signal would travel approximately $65 \mathrm{~m}$ and a $50 \mathrm{kHz}$ signal would travel $25 \mathrm{~m}$ (Schirmacher 2020).

In 2017, three validations studies were initiated using the NRG Systems technology. Schirmacher (2020) conducted a study in Ohio using six deterrent devices positioned on the nacelle. The results showed nonsignificant reductions in fatalities for hoary bats, silver-haired bats, and big brown bats, and a significant increase in fatalities for eastern red bats. A similar study was conducted in Ontario, with inconclusive results for individual species and all bats combined. A 2-year study in south Texas, using six deterrents in 2017 and five in 2018, showed significant reductions in fatalities for Brazilian free-tailed bats and hoary bats (Weaver et al. 2020).

The advancement of nacelle-mounted deterrents has improved their reliability. However, attenuation limits the extent that ultrasound can travel. At the SPL believed to deter bats ( $\sim 50-60$

\footnotetext{
${ }^{10} \mathrm{https} / / /$ www.energy.gov/sites/prod/files/2019/05/f63/GE\%20-\%20M19\%20-\%20Kinzie FINAL.pdf

11 https:/www.energy.gov/sites/prod/files/2019/05/f63/BCI\%20-\%20M20\%20-\%20Schirmacher_Hein_FINAL.pdf
} 
$\mathrm{dB})$, lower frequencies $(\sim 20 \mathrm{kHz})$ can extend beyond the tip of most existing wind turbine blades at land-based wind energy facilities, but higher frequencies $(\sim 50 \mathrm{kHz})$ may only travel half the blade length (Figure 5). Furthermore, the percent reduction of bat fatalities continues to be less than that achieved by most curtailment strategies tested. Moreover, differences in effectiveness among species remains a concern, particularly for eastern red bats, where more fatalities can occur when deterrents are operational. Research to advance both technologies is ongoing, with GE comparing the effectiveness of their deterrent technology to curtailment ${ }^{12}$ and NRG Systems exploring species-specific differences to three different deterrent signals (i.e., $20-32 \mathrm{kHz}, 38-50$ $\mathrm{kHz}$, and $20-50 \mathrm{kHz}$ ) and the relationship between bat response and intensity/distance from the source using a flight cage. ${ }^{13}$

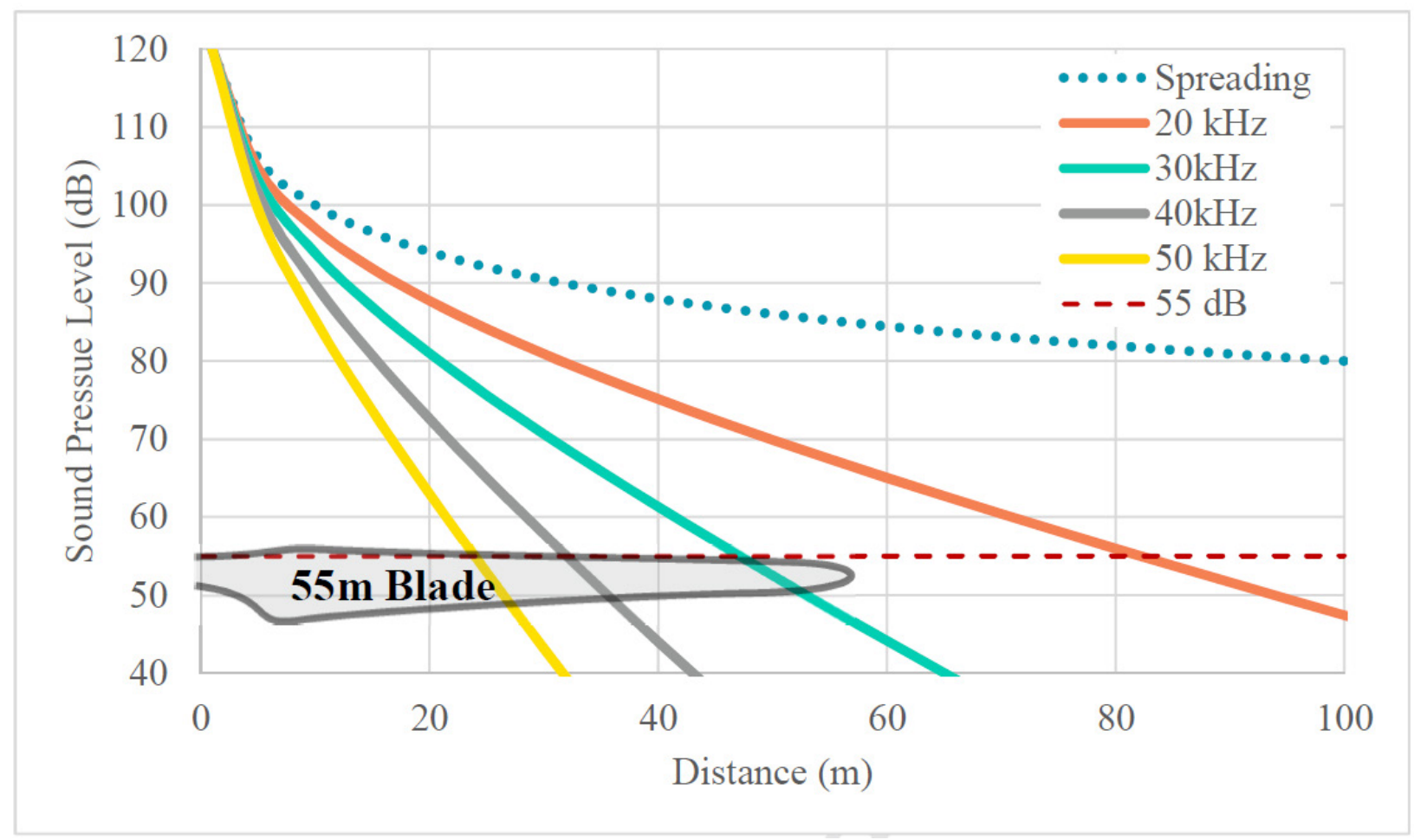

Figure 7. Sound pressure level of ultrasound produced at 20,30, 40, and $50 \mathrm{kHz}$ between 0 and $100 \mathrm{~m}$ based on a starting sound pressure level of $120 \mathrm{~dB}$ measured at $1 \mathrm{~m}$. Calculations incorporate spreading loss (dotted blue line) due to distance and mean attenuation coefficients based on hourly temperature, relative humidity, and pressure acquired from a meteorological tower at the Los Vientos Wind Energy Facility in Starr County, Texas, USA. The red dashed line represents the presumed sound pressure level $(55 \mathrm{~dB})$ necessary to deter bats. The turbine blade length of the Vestas V-110, 2-MW turbines is included for reference. From Weaver et al. 2020

\subsubsection{Blade-Mounted}

The combination of rapid attenuation of ultrasound emanating from the nacelle and the everincreasing length of wind turbines blades have led to the development of deterrent technologies

\footnotetext{
12 https://www.nationalwind.org/wp-content/uploads/2020/02/1 GE-Presentataion-for-NWCC-webinar-on-DOEsupported-bat-deterrent.pdf

${ }^{13}$ https://www.nationalwind.org/wp-content/uploads/2020/02/2_Hein_FOA1924_NWCC-Presentation.pdf
} 
that are installed on the blades themselves. Technologies for blade-mounted deterrents include passive devices or whistles that generate ultrasound from the movement of the blades and powered devices that use piezoelectric transducers.

\subsubsection{Passive}

The University of Massachusetts Amherst leads a research team developing and conducting initial trials of a passive, blade-mounted deterrent. The prototype whistles operate in various ranges, including $25-35 \mathrm{kHz}, 35-45 \mathrm{kHz}$, and $45-55 \mathrm{kHz} .{ }^{14}$ Lab-based trials showed no significant results during the y-maze assay, but during perch assay and turning assay trials, bats significantly selected the quiet perch and turned in response to the deterrent stimuli, respectively. Ground-based trials in natural settings are ongoing and experiments with whistles attached to turbines blades are forthcoming.

Iowa State University also is developing a passive blade-mounted deterrent. The system involves multiple resonators for broad spectral coverage $(20-50 \mathrm{kHz}){ }^{15}$ This project is in the early stages of development.

\subsubsection{Powered}

Frontier Wind initiated a study to develop a piezoelectric, blade-mounted acoustic deterrent that is powered by the wind turbine. The device used four subarrays each with a separate peak resonance of $25,35,45$, and $55 \mathrm{kHz}$. ${ }^{16}$ The SPL measured from the device exceeded $65 \mathrm{~dB}$ measured at $10 \mathrm{~m}$ away from the source. Initial complications with power supply and weatherization were overcome during the project, but continued delays, outside of Frontier Wind's control, resulted in a cancellation of the project (Cooper et al. 2020).

Midé Technology, a Hutchinson Company continues the exploration of a piezoelectric, blademounted deterrent. One difference from the Frontier Wind deterrent is that the Midé Technology device is designed to be self-powered. ${ }^{17}$ Simulations of the device show an $80 \mathrm{~dB}$ signal measured at $20 \mathrm{~m}$ across a $20-50 \mathrm{kHz}$ range. Initial field testing of the technology is planned for 2021.

\subsection{Ultraviolet}

The U.S. Geological Survey (USGS) is testing a flickering dim UV light source to illuminate wind turbines with the intent of changing the bats' perception of the structure. Dim UV light may be effective across greater distances relative to ultrasound, easily deployable and cost-effective. Gorresen et al. (2015a) confirmed widespread UV vision in bats. Subsequently, Gorresen et al. (2015b) reported that dim UV light reduced bat activity despite an increase in insect abundance. Results from this study warranted further testing at operational wind turbines. In 2018, the USGS

\footnotetext{
${ }^{14}$ https://www.energy.gov/sites/prod/files/2019/05/f63/UMass\%20-\%20M16\%20-\%20Sievert_draft_rt_revised.pdf

15 https:/www.nationalwind.org/wp-content/uploads/2020/02/3 Iowa-State_19241514 ISU_Sharma_Anupam_Q1_2020.pdf

${ }^{16} \mathrm{https} / /$ www.energy.gov/sites/prod/files/2019/05/f63/Frontier\%20-\%20M18\%20-\%20TBD\%20jbs_0.pdf

17 https://www.nationalwind.org/wp-content/uploads/2020/02/4_Mide_WindTurbineNREL Webinar_.pdf
} 
initiated a study at NREL's Flatirons Campus to assess how bats respond to wind turbines illuminated with flickering dim UV light. ${ }^{18}$ Results from this study are expected in 2021.

\subsection{Texture Coating}

Applying a texture coating to the surface of wind turbine towers is another potential means of disrupting how bats perceive wind turbines. Research from a Texas Christian University-led effort indicated the smooth surface of wind turbines may be misinterpreted as a drinking resource. ${ }^{19}$ The echolocation signatures from the tower resemble those of still water and may illicit an innate response in bats. Lab and flight cage experiments indicated potential effectiveness, but initial field trials at wind turbines were inconclusive (Bennet and Hale 2018).

\subsection{Considerations and Challenges}

Workshop participants shared lessons learned, challenges, and next steps for validation and adoption of deterrent technologies. Common themes are summarized below (see Appendix B for more information).

\subsubsection{Costs}

Validation studies include costs associated with developing the technology; serving as a host site; permitting; installation and maintenance of the technology; and monitoring, analysis, and report writing to verify efficacy. Costs related to adopting a technology include purchasing the technology, installation and maintenance, and compliance monitoring (if associated with listed species). These costs are not born equitably across the industry. Some operators are more willing to serve as host sites and to assume the risks associated with validation and early adoption of relatively new technologies. Although operators are the end user for deterrent technologies, innovation and advancements of solutions could be accelerated and bolstered through more robust collaboration across sectors and the supply chain. The workshop participants discussed several questions pertaining to the advancement of deterrent technologies. These included:

- How can monitoring costs be reduced when validating technology or verifying that fatality reduction targets are met? As the height of wind turbines and rotor-swept areas increase, so will the area in which fatalities may land, potentially leading to increased search-plot size and further increasing costs of validating technology. Identifying ways to reduce these costs may encourage more investments in research and adoption of verified technologies.

- How can technology vendors reduce uncertainties and risk to the consumer? Long-term operations and maintenance costs and efficacy are unknown, which makes the cost/benefit ratio challenging to define for early adopters.

- How can collaborative funding mechanisms facilitate more robust studies where costs and risks are shared among team members?

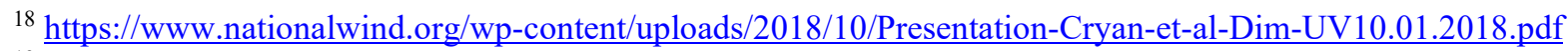

19 https://www.energy.gov/sites/prod/files/2019/05/f63/TCU\%20-\%20M17\%20-\%20Hale-Bennett.pdf
} 


\subsubsection{Technology}

Variability in turbine models, particularly blade length, and the bat species composition at a site will likely influence the efficacy of deterrent technologies. Although ultrasonic deterrent research began 14 years ago, there have been few experimental studies at operational facilities and many questions remain. Moreover, new technologies have not advanced far enough to warrant large-scale validation studies. The workshop participants discussed several questions pertaining to the advancement of deterrent technologies. These included:

- What factors impact the efficacy of deterrents (e.g., environmental conditions)?

- What are the pros and cons of retrofitting existing turbines as opposed to including technologies as part of a package with new turbines?

- How can the approach to deterrence be refined to improve species-specific efficacy without prohibitively complicating the system?

- How does increasing blade length impact how bats interact with turbines and ultrasonic deterrent signals? Does the entire rotor-swept area need to be covered?

- Will retrofitting turbine blades with deterrents impact turbine performance or compromise the lightning system?

- What is the best practice that should be adopted to measure the SPL of acoustic deterrents?

\subsubsection{Behavior and Physiology}

When bats are subjected to a deterrent stimulus, the response may be observed and quantified; however, the actual behavioral or physiological drivers may not be understood. Furthermore, the source of the perceived attraction by bats to wind turbines remains unknown, as does the most effective way to disrupt it. There remains a need to uncover what drives bat behavior at the turbine- and landscape-scale and reveal opportunities for continued improvement of deterrent solutions. The workshop participants discussed several questions pertaining to the advancement of deterrent technologies. These included:

- Why do bats, or certain species of bats, approach and interact with wind turbines? And does this phenomenon occur around other tall structures?

- How do bats perceive/process/respond to various stimuli (visual, electromagnetic, scent)?

- How do bats perceive or experience ultrasound (jamming, annoyance, pain, etc.)?

- How and why do bats shift their call frequencies?

- Will bats habituate to deterrent stimuli?

- Does age, sex, breeding status, or other factors affect how bats interact with wind turbines or respond to deterrent stimuli?

- Where along the blades do collisions occur? How can this inform optimal placement of deterrents?

\subsubsection{Regulatory}

Some companies may be more willing to bear the costs of supporting studies to validate efficacy or early adoption of verified technologies while others may wait before making investments. Currently, there is little incentive to encourage more aggressive investment in minimization solutions especially when these investments can compromise a company's competitiveness. Collaboration between wildlife regulators, public utility commissions, industry, and the 
conservation community can help identify opportunities to reframe this dynamic in a manner that manages risk across sectors and encourages more rapid solution development and adoption. The workshop participants discussed several questions pertaining to the advancement of deterrent technologies. These included:

- What are the options for operators to work with regulators to expedite permitting for research that may benefit listed species?

- How can adaptive management strategies facilitate technology testing without increasing uncertainty?

- What are the best practices for standardized reporting and statistical methods that should be adopted to ease interpretation for regulators?

- How can coordination between individual states and state and federal agencies be increased?

- What are the options for identifying suitable fatality reduction targets for non-listed bat species that are most vulnerable to wind energy development?

- What is the level of monitoring necessary to provide enough confidence to regulators to allow for the use of deterrents in place of curtailment?

\subsubsection{Validation}

There is a sense of urgency to advance a suite of solutions as quickly as possible. The following steps are recommended to efficiently progress through the TRL hierarchy to full commercialization:

1. Fundamental and applied research to inform solution development

2. Desktop analyses

3. Bench testing and laboratory tests of components and subsystems

4. Testing subsystems and fully integrated systems in a simulated environment

5. Small-scale prototype testing in relevant environment

6. Mid-scale testing in operational environment

7. Full-scale testing in operational environment.

Following this hierarchical pathway allows technology vendors to identify failure points and system weaknesses early, in a safe and low risk venue. Through this process of development, improvements are made prior to scaling up when scope and costs increase. Laboratory, groundbased, and small- to mid-scale studies (e.g., 1-3 turbine studies) can inform logistics and tactical approaches such as ideal placement, system configuration, or weatherization needs to avoid unanticipated impacts (to the system itself, wildlife, or turbine performance) later in the process. These steps minimize unanticipated complications during full wind farm scale testing. The workshop participants discussed several questions pertaining to the advancement of deterrent technologies. These included:

- Should $3^{\text {rd }}$-party testing and validation be more common?

- What methods of data collection and reporting should be standardized (e.g., measuring SPL and consistent confidence intervals)?

- How can combining different monitoring strategies maximize the value of data collection? 
- Can ultrasonic deterrents be improved with alternative sound patterns, such as short band clicks or frequency sweeps?

- To what extent can laboratory and field-based studies indicate potential effectiveness? Are these environments irrelevant if turbines are not present?

- What is the level of monitoring necessary to track long-term effectiveness (e.g., potential habituation) of a technology? 


\section{Curtailment}

Although deterrents rely on a behavioral response from bats to reduce interactions with turbines, curtailment alters turbine operations in response to suspected risk to bats. Early studies observed that bats are more active during lower wind speeds (Arnett et al. 2005) and incidence of fatality was noted to be highest during late summer and early fall across the United States and Canada (Arnett et al. 2008). These data indicated a relatively narrow window of risk based on wind speed, time of year, and time of day (i.e., night), and the potential to reduce risk by altering turbine operations (i.e., feathering turbine blades and raising cut-in speeds; Arnett et al. 2010). This practice is commonly referred to as standard or blanket curtailment. The months and wind speed thresholds prescribed have varied where standard curtailment has been implemented. Variability among curtailment strategies employed can be explained, in part, by more aggressive approaches for endangered bats that may incorporate additional months and higher cut-in speeds.

Arnett et al. (2013b) summarized the results of 10 curtailment studies. Although prescribed treatments and geographic regions varied among the studies included in the synthesis, most treatments resulted in an average 50\% reduction in fatality. The authors conclude that, although results are likely to vary based on species and characteristics of the wind regime at a given location, increasing cut-in speed between 1.5 and $3.0 \mathrm{~m} / \mathrm{s}$ above the manufacturer's cut-in speed or feathering turbine blades and slowing rotor speed up to the turbine manufacturer's cut-in speed can significantly reduce mortality. A summary for the Canadian Wind Energy Association reported observed reductions in mortality at wind speeds $\geq 4.5 \mathrm{~m} / \mathrm{s}$, but that the value of raising cut-in speeds above $4.5 \mathrm{~m} / \mathrm{s}$ is unclear because of wide and overlapping confidence intervals among studies (DNV GL 2018). At the workshop, Bat Conservation International presented preliminary findings from a follow-up synthesis expected to be published in 2021.

Although blanket curtailment has shown significant reductions in mortality, this approach leads to losses in annual energy production (AEP) and revenue as curtailed turbines do not generate electricity. Additional understanding of the actual cost (in terms of energy loss, carbon reduction, and potential contract violation issues between the facility operator and offtaker) needs to be further evaluated to understand the viability of widespread deployment of such a measure. These losses are the driving force behind the pursuit of more refined strategies that narrow the period when turbines are curtailed without sacrificing efficacy. Arnett et al. (2013b) suggest temperature, barometric pressure, and rainfall as additional potential weather variables to explore. Meteorological conditions and bat echolocation calls are among the observable variables that have been investigated as possible covariates to incorporate into curtailment regimes (Weller and Baldwin 2012; Martin et al. 2017). When additional covariates are employed to inform a more complex curtailment strategy, this is often referred to as smart curtailment. Smart curtailment is largely divided into two subcategories: fully modeled approaches and those that use real-time bat activity.

\subsection{Modeled Curtailment Approaches}

Weller and Baldwin (2012) demonstrated a method for modeling site-specific occupancy correlated with meteorological conditions. The authors encourage the use of multiple covariates to estimate presence and inform smart curtailment protocols. Behr et al. (2017) leveraged modeled bat activity and a collision model to estimate collision rate as a means for informing curtailment. They also incorporated revenue considerations to weight curtailment decisions to 
minimize economic losses. Martin et al. (2017) demonstrated decreased energy losses with the incorporation of temperature, a covariate not used by Behr et al. (2017).

These studies point to the potential to effectively reduce fatality and energy losses with the incorporation of additional covariates that can inform risk. Unfortunately, it is doubtful that a one-size-fits-all model exists. Korner-Nievergelt et al. (2013) emphasize the site-specific nature of estimating collision risk and that training data, including turbine size, species composition, and wind regime, need to be leveraged to match the site conditions. The Stantec Smart Curtailment Designer aims to meet this requirement. Acoustic data are collected a year prior to implementation of the model to assess site specific exposure rates. These data are analyzed to inform a modeled smart curtailment protocol customized for the site of interest to be implemented in subsequent years. This approach also allows for the curtailment to be customized based upon logistical or technological constraints for a given site (e.g., SCADA system capabilities). Initial studies have shown positive results and publications are forthcoming. A 15turbine study to assess this approach began in $2020 .^{20}$

Turbine integrated systems may avoid data security and SCADA compatibility complications that some after-market solutions may face. Vestas and SGRE are two OEMs that have started integrating minimization systems into their turbines. SGRE offers an integrated curtailment, or wildlife stop, option with Siemens turbines. ${ }^{21}$ The Vestas Bat Protection System is a software module available in Vestas SCADA systems. In an upcoming study, acoustic, thermal video, and fatality data will be collected and compared to weather data to inform the algorithm in the Vestas Bat Protection System software. Data collection will begin in $2021 .^{22}$

\subsection{Curtailment Informed by Real-Time Bat Activity}

Leveraging real-time acoustic data is one of the innovations that has been pursued as a smart curtailment strategy. A 2013 study in Germany was able to associate density estimates, using acoustic data, with collision risk (Korner-Nievergelt et al. 2013). Then in 2015, researchers testing the Acoustic and Thermographic Offshore Monitoring (ATOM) system ${ }^{23}$ noted that with means for data transmission, real-time smart curtailment is possible (Willmott, Forcey, and Hooton 2015). Although the technology developers for the ATOM system chose to focus use on pre- and post-construction studies as a primary application (marketed for offshore) others have continued to pursue this approach.

Normandeau Associates, Inc., with the support of collaborative funding, has been developing Turbine Integrated Mortality Reduction (TIMR ${ }^{\mathrm{SM}}$ ) since 2012 . $\mathrm{TIMR}^{\mathrm{SM}}$ is owned by the Electric Power Research Institute and uses real-time acoustic and wind speed data to inform curtailment. In a 2015 study with 10 control and 10 treatment turbines, nacelle mounted data acquisition systems were installed to collect and analyze acoustic data while nacelle anemometers supplied wind speed data. If a bat call was detected and wind speed was below $8 \mathrm{~m} / \mathrm{s}$, curtailment was

\footnotetext{
${ }^{20}$ https://www.nationalwind.org/wp-content/uploads/2020/03/1_ABIC_Stantec_AWWI_3-25-20.pdf

21 https://www.siemensgamesa.com/explore/journal/uniting-environment-and-technology

22 https://www.nationalwind.org/wp-content/uploads/2020/03/2 AWWI-VBPS-Overview-Slides-for-NWCCWebinar-032420.pdf

${ }^{23}$ https://www.normandeau.com/environmental-specialists-consultant-atom-technology/
} 
triggered. Results showed significant reductions in fatality across species (little brown bat $91.4 \%$, silver-haired bat $90.9 \%$, and hoary bat $82.5 \%$ ) with estimated revenue loss as high as $3.2 \%$ (Hayes et al. 2019). A new study was initiated in $2020 .^{24}$

Natural Power is developing the Bat Smart Curtailment system, which uses a minimum of wind speed and acoustic data to inform real-time curtailment decisions. Natural Power is embarking on a study to ensure compliance with the North American Electric Reliability Corporation Critical Infrastructure Protections, evaluate SCADA compatibility, assess mechanical loading on the turbine, and validate efficacy. ${ }^{25}$

\subsection{Considerations and Challenges}

Workshop participants shared lessons learned, challenges, and next steps for smart curtailment implementation and validation. Common themes are summarized below (see Appendix C for more information).

\subsubsection{Costs}

As with deterrents, there are numerous costs associated with curtailment $R \& D$ or adoption. These include operations and maintenance support for hosting studies, validation studies to verify efficacy, system purchase costs and whether the costs can be capitalized, equipment maintenance, and revenue losses associated with reductions in AEP. These costs are subject to extreme variation and are difficult to accurately predict because the full context is so complex. The cumulative costs associated with a study or long-term adoption of curtailment are specific to the site, curtailment strategy, and associated technology, but losses in AEP are considered to be the most significant. The significance of AEP loss depends on market structure, current price of electricity, power purchase agreement terms, and overall profitability of the site. Not all sites produce the same profit margin, so in some instances small percentages of AEP loss can have a large impact.

\subsubsection{Technology}

Variability in turbine models and the regions in which they are deployed influence both the cost and the practicality of adopting curtailment. Currently, there are more than three decades worth of turbine models installed on the landscape. Each vintage of turbine comes with a different SCADA system, hub height, rotor diameter, and rated capacity. As curtailment approaches continue to evolve, the following should be considered:

- The frequency of start and stops from a curtailment scenario can influence wear and tear on the turbine.

- Older SCADA systems are limited in the type and complexity of curtailment they can enable based upon the number of inputs the interface has capacity for.

\footnotetext{
${ }^{24} \mathrm{https}$ ://www.nationalwind.org/wp-content/uploads/2020/03/4_EPRI-DOE-TIMR-NWCC-Webinar_032620201.pdf

${ }^{25} \mathrm{https}$ ://www.nationalwind.org/wp-content/uploads/2020/03/3_DOE-NWCC-BSC-_Sutter_FINAL-UpdatedMarch-26-2020.pdf
} 
- Curtailment requirements will have a greater impact on generation in lower wind speed areas and may be compounded by the behavior and timing of activity for species that occur in these regions.

- Acoustic detectors do not always detect bats in the area (Corcoran and Weller 2018; Gorresen, Cryan, and Tredinnick 2020).

- As smart curtailment research increases (e.g. additional covariates and species-specific treatments) so does the complexity of the overall system and technological requirements, therefore increasing installation, maintenance, and capital and operational costs.

\subsubsection{Behavior and Physiology}

Although there have been several studies that investigate covariates for presence and risk, little is known about bat behavior as it relates to wind energy and the drivers behind the behavior. The workshop participants discussed several questions related to bat behavior and physiology drivers that potentially influence interactions with wind turbines. These included:

- What is the source of attraction?

- What are the species-specific responses to various environmental stimuli?

- What are the common sensory detection mechanisms that drive navigation?

- How do different weather conditions (e.g., wind speed, barometric pressure, turbulence, sheer, and temperature) influence species-specific behavior?

- How do different physiological conditions affect behavior?

- How do social cues influence behavior?

- What are the density and dispersal trends for each species across the year?

- Can migratory routes be defined?

- How does bat activity vary across a single wind energy project?

- How do landscape variables drive movement patterns?

\subsubsection{Regulatory}

Regulatory buy-in is crucial to the success of conducting studies and implementing curtailment. Currently there is no broad regulatory acceptance of smart curtailment in place of standard curtailment for listed species, but individual Habitat Conservation Plans may allow for the implementation of smart curtailment. Cross-sector collaboration is needed to determine what requirements need to be filled to move towards acceptance. Establishing basic monitoring and reporting standards may offer a pathway to acceptance and adoption. Monitoring per individual facility during only a 1 to 2 year period offers limited insight for understanding wind energy impacts on bats at larger scales, making it difficult for regulators to define reduction targets and requirements To ensure reduction targets are achieved, large-scale, coordinated monitoring (e.g., random testing at a continental level) may offer a cost-effective option to supply decision makers with the information they need.

\subsubsection{Validation}

There is a need for greater consistency across research projects. The current variability in aspects like where measurements are taken and in reporting make it difficult to interpret results in the broader context of time and geography. For example, wind speed measurements are typically taken from nacelle anemometers, which are notoriously inaccurate due to turbine wakes. There are strategies to correct for these inaccuracies, but they are imperfect and variable. 
Measurements taken from meteorological towers are similarly vulnerable to inaccuracies. This presents the confounding factor that $5.0 \mathrm{~m} / \mathrm{s}$ at one site does not necessarily equal $5.0 \mathrm{~m} / \mathrm{s}$ at another. Alternative methods to accurately measure wind speed in a manner that is replicable across sites would allow for greater consistency. Furthermore, increased standardization when collecting data and reporting results will allow the broader community to better leverage research efforts and increase confidence in results. 


\section{Recommendations}

Minimization strategies are in various stages of development, from those conducting preliminary lab and field trials to others that are commercially available and implemented. New ideas will surface in the coming years. Testing a variety of approaches will help the wind and wildlife community achieve our collective renewable energy and conservation goals, as there is likely no single solution to satisfy the diversity of scenarios. Cost-effective curtailment strategies may be more effective in some situations and other sites may require deterrents. In other circumstances, a combination of technologies may be necessary. Examples include combining nacelle and blade-mounted deterrents to potentially maximize the ensonified airspace around a wind turbine or using smart curtailment in combination with dim UV light.

Participants indicated the need for creative policy and financial systems and strategic partnerships to foster better collaboration and nimble adaptation to change. This will involve forming new networks of partners, reducing uncertainty and risk for industry participation, incentivizing technology development, increasing the pace of R\&D and reporting, and establishing consistent and substantial funding sources. These approaches will reduce technological, regulatory, and economic barriers, and help improve existing strategies and advance others up the TRL hierarchy. The recommendations offered by workshop participants are summarized below.

\subsection{General Recommendations}

\subsubsection{Communication}

Communication is essential for complex operations such as these. A dedicated project manager is recommended to coordinate activities among all project team members, which can include operators, technology vendors, biologists, statisticians, and OEMs. It also is important to engage early with those outside of the core project team, such as state and federal regulators. Engaging in multistakeholder collaboratives (e.g., BWEC and American Wind Wildlife Institute) can help share perspectives, build relationships, and discuss priorities. Networking activities, such as workshops, are necessary to disseminate study results and lessons learned and address misperceptions. There also is an urgency to disseminate research findings more rapidly to keep pace with technology development.

\subsubsection{Bat Biology and Physiology}

There is a clear need to gain a better understanding of the behavioral and physiological drivers of risk. This information is crucial to designing more effective minimization technologies. Several key questions persist:

- Why do bats approach and interact with wind turbines?

- What are the species-specific responses to wind turbines and minimization strategies

- How are bats moving at broad spatial and temporal scales?

Answering these questions will require a suite of monitoring technologies that can be deployed at the turbine, wind energy facility, or landscape scale. 


\subsubsection{Consistency}

Consistency in data collection and reporting is essential for comparing the effectiveness within and among minimization strategies. Examples include:

- Using $95 \%$ confidence intervals

- Measuring SPL at $1 \mathrm{~m}$ distance from the deterrent signal in an anechoic chamber

- Explore alternative methods to accurately measure wind speed in a manner that is replicable and using measurements that are comparable across sites.

\subsubsection{Project Logistics and Costs}

Project logistics and costs are interrelated. Understanding both is critical to the success of a project, but may not be fully understood, particularly for those who have not been involved in these large-scale studies. It is important to recognize the time and labor required for these experimental studies. Some labor expenses are relatively easy to quantify based on the study design (e.g., searching 16 turbines with $100 \mathrm{~m}$ radius plots for 90 days equals $\$ \mathrm{X}$ ). Other costs may be somewhat hidden or more difficult to quantify, such as the time required for operational staff to install, maintain, and remove a technology on 16 wind turbines for 90 days, or crop compensation, which can vary by region and market prices.

\subsubsection{Funding}

Given how relatively expensive experimental studies are, diverse funding mechanisms are recommended to reduce cost barriers. Funding needs to be more strategic. It is better to direct funds towards a single, well-designed study rather than disperse those same funds across multiple studies that lack statistical power. Pooling funding and resources is necessary for largescale projects so that no single entity bears the entire financial burden. This has been successful in recent funding opportunity announcements by WETO ${ }^{26}$ where government funding is combined with cost-share from project team members. Another recent funding mechanism is the Wind Wildlife Research Fund ${ }^{27}$ which brings a multitude of industry partners together to collectively fund priority research.

\subsection{Deterrent Recommendations}

Deterrents pose a promising alternative or complementary measure to curtailment, particularly in low wind regimes. Deterrents will become increasingly more important with taller turbines with longer blades that can operate at lower wind speeds. Nacelle-mounted ultrasonic deterrents may have the greatest challenge scaling up to larger turbines with larger rotor-swept areas. Deterrents are still a relatively new minimization strategy, and novel technologies (low-mid TRLs) will require more robust experiments and monitoring.

Workshop participants highlighted the need to address the major barriers for advancing deterrents, most notably the major data gaps on species-specific efficacy, high research and monitoring costs, and few incentives to test new technologies. Participants shared an array of

\footnotetext{
${ }^{26} \mathrm{https}: / /$ www.energy.gov/eere/solar/funding-opportunities

${ }^{27}$ https://awwi.org/wind-wildlife-research-fund/
} 
potential approaches to advance deterrent technologies. Overall, participants called for broader collaboration and greater flexibility as technologies, research, and policies evolve in tandem.

In Table 3 we combine priorities established by the BWEC from the $5^{\text {th }}$ Science Meeting in 2018, with those introduced at this workshop.

Table 3. Deterrent Priorities Established by the Bats and Wind Energy Cooperative at the $5^{\text {th }}$ Science Meeting in June 2018 Plus New Objectives Introduced at the State of the Science and Technology for Minimizing Impacts to Bats from Wind Energy, November 13-14, 2019

\begin{tabular}{|c|c|c|c|}
\hline Priority & Objective & Action & Source \\
\hline \multirow[t]{11}{*}{$\begin{array}{c}\text { Deterrent } \\
\text { Technologies }\end{array}$} & $\begin{array}{l}\text { Advance deterrent } \\
\text { technologies }\end{array}$ & Conduct additional experimental studies & $\begin{array}{l}\text { BWEC priority } \\
\text { reiterated at the } \\
\text { workshop }\end{array}$ \\
\hline & $\begin{array}{l}\text { Advance species-specific } \\
\text { knowledge }\end{array}$ & $\begin{array}{l}\text { Support species-specific assessment of } \\
\text { the effectiveness of deterrent } \\
\text { technologies }\end{array}$ & $\begin{array}{l}\text { BWEC priority } \\
\text { reiterated at the } \\
\text { workshop }\end{array}$ \\
\hline & $\begin{array}{l}\text { Advance understanding of } \\
\text { the effective range of } \\
\text { deterrents }\end{array}$ & $\begin{array}{l}\text { Work with technology providers to } \\
\text { provide greater coverage around the } \\
\text { wind turbines }\end{array}$ & $\begin{array}{l}\text { BWEC priority } \\
\text { reiterated at the } \\
\text { workshop }\end{array}$ \\
\hline & $\begin{array}{l}\text { Study effectiveness of } \\
\text { combined methods }\end{array}$ & $\begin{array}{l}\text { Conduct experimental studies using } \\
\text { combined approaches (e.g., curtailment } \\
\text { and deterrents OR combination of } \\
\text { deterrents) }\end{array}$ & $\begin{array}{l}\text { BWEC priority } \\
\text { reiterated at the } \\
\text { workshop }\end{array}$ \\
\hline & Advance UV technology & $\begin{array}{l}\text { Conduct further development and } \\
\text { testing of UV technology }\end{array}$ & $\begin{array}{l}\text { BWEC priority } \\
\text { reiterated at the } \\
\text { workshop }\end{array}$ \\
\hline & $\begin{array}{l}\text { Consider whether } \\
\text { monitoring should } \\
\text { combine mortality and } \\
\text { behavioral monitoring }\end{array}$ & $\begin{array}{l}\text { Broad collaboration among stakeholders } \\
\text { Greater sample size of turbines } \\
\text { previously used in thermal video camera } \\
\text { studies }\end{array}$ & $\begin{array}{l}\text { Introduced at } \\
\text { the workshop }\end{array}$ \\
\hline & & $\begin{array}{l}\text { Advanced processing software (e.g., } \\
\text { machine learning) to identify and track } \\
\text { bat observations }\end{array}$ & \\
\hline & $\begin{array}{l}\text { Foster cross-sector } \\
\text { collaboration throughout }\end{array}$ & $\begin{array}{l}\text { Strong management leadership and } \\
\text { coordination }\end{array}$ & $\begin{array}{l}\text { Introduced at } \\
\text { the workshop }\end{array}$ \\
\hline & the supply chain & $\begin{array}{l}\text { Host small workshops among OEMs, } \\
\text { technology vendors, and operators }\end{array}$ & \\
\hline & $\begin{array}{l}\text { Identify the species- } \\
\text { specific risk "zones" } \\
\text { around turbines }\end{array}$ & $\begin{array}{l}\text { Using thermal cameras and acoustic } \\
\text { detectors to monitor species-specific } \\
\text { responses to control and deterrent } \\
\text { treatments }\end{array}$ & $\begin{array}{l}\text { Introduced at } \\
\text { the workshop }\end{array}$ \\
\hline & & Can be paired with validation studies & \\
\hline
\end{tabular}




\begin{tabular}{|c|c|c|c|}
\hline Priority & Objective & Action & Source \\
\hline $\begin{array}{l}\text { Bat Behavior } \\
\text { at the } \\
\text { Turbine- or } \\
\text { Facility-scale }\end{array}$ & $\begin{array}{l}\text { Develop standards and } \\
\text { methods for newer } \\
\text { techniques and } \\
\text { technologies (e.g., } \\
\text { thermal cameras) }\end{array}$ & $\begin{array}{l}\text { BWEC Working Group to develop } \\
\text { thermal video monitoring strategy } \\
\text { Expanded information sharing }\end{array}$ & $\begin{array}{l}\text { BWEC priority } \\
\text { reiterated at the } \\
\text { workshop }\end{array}$ \\
\hline
\end{tabular}

\subsection{Curtailment Recommendations}

Companies currently use blanket curtailment as a minimization strategy, and it is considered the baseline for comparison with other strategies. Several new systems and technologies for smart curtailment may help companies curtail only when bats are present or likely present, thus reducing the time turbine operations are altered. Improving curtailment strategies will help strike the balance between fatality reduction and energy production losses.

Many of the challenges for advancing deterrent technology also relate to curtailment; however, some challenges pose greater hurdles for curtailment. For example, the need to meet contractual power targets or balancing the need to understand the economic impact with safeguarding proprietary power production data. Workshop participants indicated smart curtailment offers promising applications in certain situations; however, participants recommended continued studies on improving blanket curtailment to address remaining data gaps (e.g., fatality reduction at lower cut-in speeds).

Below we combine priorities established by the BWEC from the $5^{\text {th }}$ Science Meeting in 2018, with those introduced at this workshop. 
Table 4. Operational Minimization and Smart Curtailment Priorities Established by the Bats and Wind Energy Cooperative at the $5^{\text {th }}$ Science Meeting in June 2018 Plus New Objectives Introduced at the State of the Science and Technology for Minimizing Impacts to Bats from Wind Energy on November 13-14, 2019

\begin{tabular}{|c|c|c|c|}
\hline Priority & Objective & Action & Source \\
\hline \multirow[t]{7}{*}{$\begin{array}{l}\text { Operational } \\
\text { Minimization \& } \\
\text { Smart } \\
\text { Curtailment }\end{array}$} & $\begin{array}{l}\text { Summarize results from } \\
\text { curtailment strategies }\end{array}$ & $\begin{array}{l}\text { 1) Summarize effectiveness of } \\
\text { curtailment studies; 2) Assess species- } \\
\text { specific responses to curtailment; } 3 \text { ) } \\
\text { Quantify industry implementation of } \\
\text { curtailment strategies; and 4) Identify } \\
\text { barriers to adoption and ways to } \\
\text { increase implementation }\end{array}$ & BWEC priority \\
\hline & $\begin{array}{l}\text { Replicate recent "smart" } \\
\text { curtailment studies }\end{array}$ & $\begin{array}{l}\text { 1) Conduct "smart" curtailment studies } \\
\text { across landscapes, species, and turbine } \\
\text { models; and 2) Develop and standardize } \\
\text { metrics and parameters for reporting }\end{array}$ & $\begin{array}{l}\text { BWEC priority, } \\
\text { reiterated at } \\
\text { the workshop }\end{array}$ \\
\hline & $\begin{array}{l}\text { Verify impact of } \\
\text { feathering up to the } \\
\text { manufacturer's cut-in } \\
\text { speed }\end{array}$ & $\begin{array}{l}\text { Study effectiveness of feathering up to } \\
\text { cut-in speed for different species and } \\
\text { turbine models }\end{array}$ & $\begin{array}{l}\text { BWEC priority, } \\
\text { reiterated at } \\
\text { the workshop }\end{array}$ \\
\hline & $\begin{array}{l}\text { Impact reduction } \\
\text { decision support tool }\end{array}$ & $\begin{array}{l}\text { Consider feasibility of a support tool to } \\
\text { assist in designing practicable } \\
\text { curtailment strategies for different } \\
\text { scenarios }\end{array}$ & $\begin{array}{l}\text { BWEC priority, } \\
\text { reiterated at } \\
\text { the workshop }\end{array}$ \\
\hline & $\begin{array}{l}\text { Explore opportunities to } \\
\text { offset curtailment costs } \\
\text { (e.g., energy storage, } \\
\text { wake steering, and } \\
\text { other wind farm control) }\end{array}$ & $\begin{array}{l}\text { Investments in energy storage } \\
\text { Collect data to show the effectiveness of } \\
\text { wind farm control and wake steering to } \\
\text { maximize energy generation during } \\
\text { normal operation }\end{array}$ & $\begin{array}{l}\text { Introduced at } \\
\text { the workshop }\end{array}$ \\
\hline & $\begin{array}{l}\text { Pool resources to } \\
\text { conduct fewer but more } \\
\text { robust studies }\end{array}$ & $\begin{array}{l}\text { Broad collaboration among stakeholders } \\
\text { Sharing of data, methods, and multiple } \\
\text { project access }\end{array}$ & $\begin{array}{l}\text { Introduced at } \\
\text { the workshop }\end{array}$ \\
\hline & $\begin{array}{l}\text { Obtain data to better } \\
\text { inform timing and } \\
\text { conditions of collisions } \\
\text { (weather, turbulence, } \\
\text { turbine activity) }\end{array}$ & $\begin{array}{l}\text { Develop and use tools with high } \\
\text { resolution (particularly for identifying } \\
\text { species) }\end{array}$ & $\begin{array}{l}\text { Introduced at } \\
\text { the workshop }\end{array}$ \\
\hline
\end{tabular}




\section{Priority}

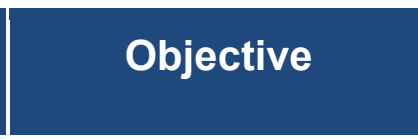

Bat Behavior at the Landscape Scale
Research bat movement patterns on larger spatial scales

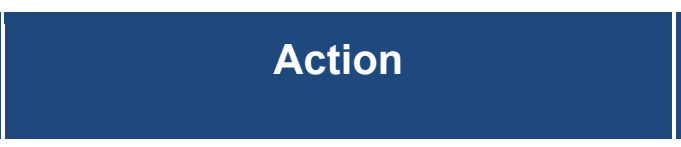

Identify studies that advance the understanding of temporal and spatial BWEC priority

movements of bats across the landscape the workshop to inform minimization strategies

Encourage wind-wildlife community to place Motus or other receivers on met towers or other structures on sites to gather movement data across sites

Continue tagging larger numbers of bats to determine movement patterns

\section{Source}




\section{References}

AFWA and USFWS (Association of Fish and Wildlife Agencies and the U.S. Fish and Wildlife Service). 2007. Wind Power Siting Regulations and Wildlife Guidelines in the United States. http://batsandwind.org/wp-content/uploads/afwastsitsum.pdf.

Annoni, J., C. Bay, K. Johnson, E. Dall'Anese, E. Quon, T. Kemper, and P. Fleming. 2019. "Wind direction estimation using SCADA data with consensus-based optimization." Wind Energy Science. 4, 355-368. https://doi.org/10.5194/wes-4-355-2019.

Arnett, E. B., W. P. Erickson, J. Kerns, and J. Horn. 2005. Relationships between bats and wind turbines in Pennsylvania and West Virginia: an assessment of fatality search protocols, patterns of fatality, and behavioral interactions with wind turbines. A final report prepared for the Bats and Wind Energy Cooperative. http://batsandwind.org.

Arnett, E. B., W. K. Brown, W. P. Erickson, J. K. Fielder, B. L. Hamilton, T. H. Henry, A. Jain, G.D. Johnson, J. Kerns, R. R. Koford, C. P. Nicholson, T. J. O'Connell, M. D. Piorkowski, and R. D. Tankersley, Jr. 2008. "Patterns of Bat Fatalities at Wind Energy Facilities in North America." The Journal of Wildlife Management. 72: 61-78. Doi:10.2193/2007-221. https://wildlife.onlinelibrary.wiley.com/doi/pdf/10.2193/2007-221.

Arnett, E. B., M. M. P. Huso, M. R. Schirmacher, and J. P. Hayes. 2010. "Altering turbine speed reduces bat mortality at wind-energy facilities." Frontiers in Ecology and the Environment. 9:209-214. https://doi.org/10.1890/100103.

Arnett, E. B., and E. Baerwald. 2013. "Impacts of Wind Energy Development on Bats: Implications for Conservation." In Bat Evolution, Ecology, and Conservation, edited by R. Adams and S. Pedersen, 435-456. New York: Springer.

Arnett, E. B., C. D. Hein, M. R. Schirmacher, M. M. P. Huso, and J. M. Szewczak. 2013 a. "Evaluating the Effectiveness of an Ultrasonic Acoustic Deterrent for Reducing Bat Fatalities at Wind Turbines." PloS ONE. 8(6): e65794. https://doi.org/10.1371/journal.pone.0065794.

Arnett, E. B., G. D. Johnson, W. P. Erickson, and C. D. Hein. 2013b. A Synthesis of Operational Mitigation Studies to Reduce Bat Fatalities at Wind Energy Facilities in North America. A report submitted to the National Renewable Energy Laboratory. Bat Conservation International. Austin, Texas. https://www.energy.gov/sites/prod/files/2015/03/f20/Operational-Mitigation-SynthesisFINAL-REPORT-UPDATED.pdf.

AWWI (American Wind Wildlife Institute). 2018. AWWI White Paper: Integration of Wildlife Detection and Deterrent Systems in Wind Power Plants. Washington, D.C. https://awwi.org/resources/technology-integration-white-paper/.

Behr, O., R. Brinkmann, K. Hichradel, J. Mages, F. Korner-Nievergelt, I. Niermann, M. Reich, R. Simon, N. Weber, and M. Nagy. 2017. "Mitigating Bat Mortality with Turbine-Specific Curtailment Algorithms: A Model Based Approach." Wind Energy and Wildlife Interactions, pp. 135-16010.11007/978-3-319-51272-3_8. 
Bennett, V., and A. Hale. 2018. Texturizing Wind Turbine Towers to Reduce Bat Mortality. U.S. Department of Energy, DE-EE0007033. Doi: 10.2172/1502997.

BWEC (Bats and Wind Energy Cooperative). 2018. Proceedings from the $5^{\text {th }}$ Science Meeting. http://batsandwind.org/wp-content/uploads/BWEC-2018-Science-MeetingProceedings_FINAL.pdf

Cole, W., N. Gates, T. Mai, D. Greer, and P. Das. 2019. 2019 Standard Scenarios Report: A U.S. Electricity Sector Outlook (Technical Report). Golden, CO: National Renewable Energy Laboratory. NREL/TP-6A20-74110. https://www.nrel.gov/docs/fy20osti/74110.pdf.

Cooper, D., T. Green, M. Miller, and E. Rickards. 2020. Bat Impact Minimization Technology. Prepared for California Energy Commission. Publication Number: CEC-500-2020-008. https://ww2.energy.ca.gov/2020publications/CEC-500-2020-008/CEC-500-2020-008.pdf.

Corcoran, A. J., and T. J. Weller. 2018. "Inconspicuous echolocation in hoary bats (Lasiurus cinereus)." Proceedings of the Royal Society B 285: 20180441.

http://dx.doi.org/10.1098/rspb.2018.0441.

Cryan, P. M., and R. M. R. Barclay. 2009. "Causes of bat fatalities at wind turbines: Hypotheses and predictions. " Journal of Mammalogy. 90: 1330-1340. https://doi.org/10.1644/09-MAMM-S076R1.1.

Cryan, P. M., P. M. Gorresen, C. D. Hein, M. R. Schirmacher, R. H. Diehl, M. M. Huso, D. T. S. Hayman, P. D. Fricker, F. J. Bonaccorso, D. H. Johnston, K. Heist, and D. C. Dalton. 2014. "Behavior of bats at wind turbines." Proceedings of the National Academy of Sciences 111: 15,126-15,131. https://doi.org/10.1073/pnas.1406672111.

DNV GL. 2018. Wind energy and bat conservation - a review by the Canadian Wind Energy Association. Document No. 10017086-HOU-R-01-D. https://canwea.ca/windfacts/wildlife/wind-energy-and-bat-conservation-review/.

Draxl, C., B. S. Hodge, A. Clifton, and J. McCaa. 2015. "The Wind Integration National Dataset (WIND) Toolkit.” Applied Energy 151: 355366. DOI: 10.1016/j.apenergy.2015.03.121.

Gorresen, P. M., P. Cryan, D. C. Dalton, S. Wolf, and F. J. Bonaccorso. 2015a. "Ultraviolet Vision May be Widespread in Bats." Acta Chiropterologica 17: 193-198. Doi: 10.3161/15081109ACC2015.17.1.017.

Gorresen, P. M., P. M. Cryan, D. C. Dalton, S. Wolf, J. A. Johnson, C. M. Todd, and F. J. Bonaccorso. 2015b. "Dim ultraviolet light as a means of deterring activity by the Hawaiian hoary bat Lasiurus cinereus semotus." Endangered Species Research 28:249-257. Doi: $10.3354 /$ esr00694.

Gorresen, P., P. Cryan, and G. Tredinnick. 2020. "Hawaiian hoary bat (Lasiurus Cinereus Semotus) behavior at wind turbines on Maui." Hawaii Cooperative Studies Unit. http://hdl.handle.net/10790/5280. 
Hayes, M. A., L. A. Hooton, K. L. Gilland, C. Grandgent, R. L. Smith, S. R. Lindsay, J. D. Collins, S. M. Schumacher, P. A. Rabie, J. C. Gruver, and J. Goodrich-Mahoney. 2019. "A smart curtailment approach for reducing bat fatalities and curtailment time at wind energy facilities." Ecological Applications. https://doi.org/10.1002/eap.1881.

Hein, C. D., J. Gruver, and E. B. Arnett. 2013. Relating Pre-Construction Bat Activity and PostConstruction Bat Fatality to Predict Risk at Wind Energy Facilities: A Synthesis. A report submitted to the National Renewable Energy Laboratory. Bat Conservation International, Austin, TX, USA. https://tethys.pnnl.gov/publications/relating-pre-construction-bat-activity-postconstruction-bat-fatality-predict-risk.

Hein, C. D. 2017. "Monitoring bats." In Wildlife and Wind Farms, Conflicts and Solutions, Volume 2, Onshore: Monitoring and Mitigations. Exeter, UK: Pelagic Publishing.

Hein, C. D., and A. M. Hale. 2019. "Wind energy effects on bats." In Renewable Energy and Wildlife Conservation, edited by C. E. Moorman, S. M. Grodsky, and P. Rupp. Johns Hopkins University Press, Baltimore, Maryland, USA.

Hoen, B. D., J. E. Diffendorfer, J. T. Rand, L. A. Kramer, C. P. Garrity, and H. E. Hunt. 2020. United States Wind Turbine Database (ver. 3.0.1, May 2020): U.S. Geological Survey, American Wind Energy Association, and Lawrence Berkeley National Laboratory data release. https://doi.org/10.5066/F7TX3DN0.

Huzzen B. E., A. M. Hale, and V.J. Bennett. 2020. "An effective survey method for studying volant species activity and behavior at tall structures." PeerJ 8:e8438 DOI 10.7717/peerj.8438.

Kinzie, K., A. Hale, V. Bennett, B. Romano, J. Skalski, and K. Coppinger. 2018. Final Technical Report; Ultrasonic Bat Deterrent Technology. U.S. Department of Energy, DE-EE0007035. https://www.osti.gov/servlets/purl/1484770.

Korner-Nievergelt, F., R. Brinkmann, I. Niermann, and O. Behr. 2013. "Estimating Bat and Bird Mortality Occurring at Wind Energy Turbines from Covariates and Carcass Searches Using Mixture Models.” PLoS ONE 8:e67997. https://doi.org/10.1371/journal.pone.0067997.

Kunz, T. H., E. B. Arnett, W. P. Erickson, A. R. Hoar, G. D. Johnson, R. P. Larkin, M. D. Strickland, R. W. Thresher, and M. D. Tuttle. 2007. "Ecological impacts of wind energy development on bats: questions, research needs, and hypotheses." Frontiers in Ecology and Evolution 5: 315-324. https://doi.org/10.1890/1540-9295(2007)5[315:EIOWED]2.0.CO;2.

Lawrence, B. D., and J. A. Simmons. 1982. "Measurements of Atmospheric Attenuation at Ultrasonic Frequencies and the Significance for Echolocation by Bats." Journal of the Acoustic Society of America. 71: 585-590. Doi: 10.1121/1.387529.

Martin, C. M., Ed. B. Arnett, R. D. Stevens, and M. C. Wallace. 2017. "Reducing bat fatalities at wind facilities while improving the economic efficiency of operational mitigation." Journal of Mammalogy 98: 378-385. https://doi.org/10.1092/jmammal/gyx005. 
Romano, W. B., J. R. Skalski, R. L. Townsend, K. W. Kinzie, K. D. Coppinger, and M. F. Miller. 2019. "Evaluation of an acoustic deterrent to reduce bat mortalities at an Illinois wind farm.” Wildlife Society Bulletin. https://doi.org/10.1002/wsb.1025.

Schirmacher, M. R. 2020. Evaluating the Effectiveness of Ultrasonic Acoustic Deterrents in Reducing Bat Fatalities at Wind Energy Facilities. U.S. Department of Energy, DE-EE0007036.

Sinclair, K., and E. DeGeorge. 2016. Framework for Testing the Effectiveness of Bat and Eagle Impact-Reduction Strategies at Wind Energy Projects (Technical Report). Golden, CO: National Renewable Energy Laboratory. NREL/TP-5000-65624. https://www.nrel.gov/docs/fy16osti/65624.pdf.

Skov Nielsen, K., D. Young, and S. Webster. 2019. Guidance for Potential Hosts of WindWildlife Technologies and Strategies. Washington, D.C. American Wind Wildlife Institute. https://awwi.org/resources/host-site-guidance/.

Spanjer, G. R. 2006. Responses of the big brown bat, Eptesicus fuscus, to an acoustic deterrent device in a lab setting. A report submitted to the Bats and Wind Energy Cooperative and the Maryland Department of Natural Resources. Bat Conservation International. Austin, TX. https://tethys.pnnl.gov/sites/default/files/publications/Spanjer-2006.pdf.

Solick, D., D. Pham, K. Nasman, and K. Bay. 2020. "Bat activity rates do not predict bat fatality rates at wind energy facilities." Acta Chiropterologica 22: 135-146.

Szewczak, J. and E. B. Arnett. 2006. Preliminary Field Test Results of an Acoustic Deterrent with the Potential to Reduce Bat Mortality from Wind Turbines. A report submitted to the Bats and Wind Energy Cooperative. Bat Conservation International. Austin, TX. https://tethys.pnnl.gov/publications/preliminary-field-test-results-acoustic-deterrent-potentialreduce-bat-mortality-wind.

Szewczak, J., and E. Arnett. 2007. Field Test Results of a Potential Acoustic Deterrent to Reduce Bat Mortality from Wind Turbines. Report submitted to the Bats and Wind Energy Cooperative and Bat Conservation International, Austin, TX. https://tethys.pnnl.gov/publications/field-testresults-potential-acoustic-deterrent-reduce-bat-mortality-wind-turbines.

Weller, T. J., and J. A. Baldwin. 2012. "Using Echolocation Monitoring to Model Bat Occupancy and Inform Mitigations at Wind Energy Facilities." The Journal of Wildlife Management. 76: 619-631. DOI: 10.1002/jwmg.260.

Weller, T. J., K. T. Castle, F. Liechti, C. D. Hein, M. R. Schirmacher, and P. M. Cryan. 2016. "First Direct Evidence of Long-distance Seasonal Movements and Hibernation in a Migratory Bat." Scientific Reports. 6:34585. https://doi.org/10.1038/srep34585.

WEST (Western EcoSystems Technology, Inc.). 2019. Regional summaries of wildlife fatalities at wind facilities in the United States. 2019 report from the Renew Database. Published by WEST, Inc., Cheyenne, WY. https://www.west-inc.com/wpcontent/uploads/2020/06/WEST_2019_RenewWildlifeFatalitySummaries.pdf 
Willmott, J. R., G. M. Forcey, and L. A. Hooton. 2015. "Developing an Automated Risk Management Tool to Minimize Bird and Bat Mortality at Wind Facilities." Ambio. 44:S557S571. DOI: 10.1007/s13280-015-0707.

Wiser, R. H., and M. Bolinger. 2019. 2018 Wind Technologies Market Report. U.S. Department of Energy Office of Energy Efficiency and Renewable Energy.

https://www.energy.gov/sites/prod/files/2019/08/f65/2018\%20Wind\%20Technologies\%20Marke t\%20Report \%20FINAL.pdf. 


\section{Appendix A. Workshop Details}

A workshop was convened in November 2019 to review the State of the Science and Technology for Minimizing Impacts to Bats from Wind Energy. Stakeholders were invited to present and discuss current impact minimization measures that are, or can be, used to reduce bat fatalities at wind energy facilities; status of R\&D of minimization measures; opportunities to optimize and improve effectiveness; and potential emerging or novel methods to investigate or pursue.

\section{Table A1. Workshop Agenda}

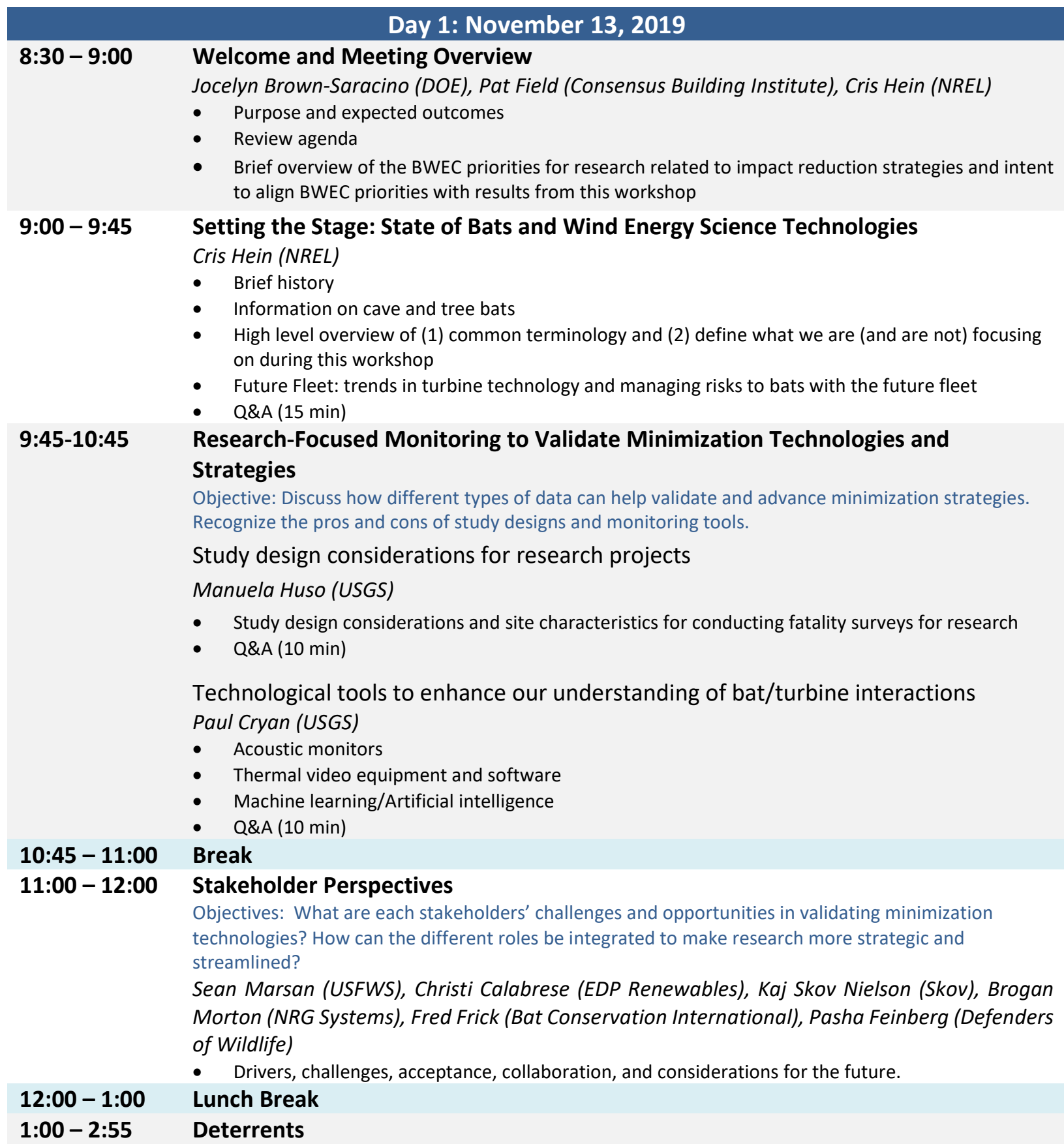


Objective: To understand challenges, perspectives and next steps for deterrent technology development and validation

History of Deterrents, Current Research and Priorities (10 min)

Cris Hein (NREL)

Low- to Mid-Technology Readiness Level

Sauro Liberatore (Mide' Technologies), Paul Cryan (USGS), Amanda Hale (Texas Christian University)

- $\quad$ Blade-mounted acoustic deterrents (10 $\mathrm{min})$

- Ultraviolet (10 min)

- Texture coating (10 min)

- Q\&A

High Technology Readiness Level

Michael Schirmacher (Bat Conservation International)

- Nacelle-mounted deterrents (15 min)

- Q\&A

Panel Discussion (45 min)

Laura Nagy (Avangrid Renewables), Brogan Morton (NRG Systems), Jared Spence (GE), and Scott Johnson (Siemens Gamesa)

- Lessons learned, benefits and risks, and considerations for validation, integration and effective communication.

2:55-3:10

Break

$3: 10-4: 15$

Deterrent Breakout Session

Objective: To explore challenges, gaps, perspectives and next steps for deterrent technology development and validation.

- What behavioral and physiological research questions remain that may help improve the performance of ultrasonic deterrents and how do we prioritize?

- What are the technological, regulatory and economic barriers to R\&D and how do we overcome them?

- How will technologies adapt to taller turbines with longer blades?

- Novel or 'outside the box' ideas for deterring bats

4:15 - 5:15 Report out from Breakout Session 1 (5 mins per table)

- $\quad$ Key themes and highlights.

5:15 - 5:30 Recap and Setting the Stage for Day 2

Pat Field (CBI)

5:30 Adjourn

Keep name badge and bring back the next day. You will need for security check-in on day 2.

\section{Day 2: November 14, 2019}

8:30 - 8:45 Recap and Introduction

Pat Field (CBI)

- Recap of Day 1

Review of Day 2 Agenda

8:45-10:30 Curtailment

Objective: To understand challenges, perspectives and objectives/next steps for smart curtailment implementation and validation.

Synthesis of curtailment studies (10 min)

Michael Whitby (Bat Conservation International)

Approaches

Mark Hayes (Normandeau), Trevor Peterson (Stantec)

- $\quad$ Real time bat activity (e.g., TIMR) (15 min)

- Modeling bat activity approaches (15 $\mathrm{min})$

- Q\&A 
10:30 - 10:45

10:45 - 11:45

$11: 45-12: 30$

$12: 30-1: 30$

1:30 - 3:15

Panel Discussion (45 min)

Janine Crane (NextEra), Galen Maclaurin (NREL), Taylor Parsons (DNV GL), Kaj Skov Nielsen

(Skov), Chrissy Sutter (Natural Power)

Lessons learned, economic considerations, barriers to implementation and opportunities for the future.

Break

Smart Curtailment Breakout Session

Objective: To explore challenges, perspectives and objectives/next steps for smart curtailment implementation and validation.

- What behavioral research questions remain and how do we prioritize?

- What are the technological and economic barriers to R\&D and how do we overcome them?

- How will strategies adapt to turbines that operate at lower wind speeds and new turbine spacing? Novel or 'outside the box' ideas for smart curtailment

Report out from Breakout Session \#2

Key themes and highlights.

Lunch Break

Deep Dive into Validation of Curtailment Systems and Deterrent Technologies

(40 min)

Manuela Huso (USGS), Scott Pruitt (USFWS), Jenny Mclvor (Berkshire Hathaway Energy),

Amanda Hale (Texas Christian University)

- Methodological, statistical, logistical, and financial considerations for conducting a validation study.

Facilitated Discussion Groups (60 min)

Deterrents approaches and challenges group

- $\quad$ Logical stages in developing a technology

○ Bench testing

- Preliminary field trials

- Wind farm scale testing.

- Geographic and temporal scales

- $\quad$ Species-specific effectiveness

- Track efficacy after deployment

Smart curtailment approaches and challenges group

- Logical stages in developing a strategy

- Identify probable covariates

- Preliminary studies or modeling

- Wind farm scale testing.

- Geographic and temporal scales

- $\quad$ Species-specific effectiveness

Track efficacy after deployment

3:15-3:30

Break

3:30-4:15

Deep Dive into Technology Integration with Turbines and Using Multiple Technologies in Concert

Bob Thresher (NREL), Greg Aldrich (Duke Energy), Jen King (NREL), Stu Webster (AWWI), Jeff

Eberling (Siemens Gamesa)

Lessons learned, collaboration and opportunities for the future.

4:15 - 4:45 Integrating with Bats and Wind Priorities \& Research

Pat Field (CBI)

- Identify the major priorities, gaps and needs as discussed throughout the State of the Science forum and compare with BWEC priorities

- Introduce BWEC working groups and engagement opportunities

Other engagement opportunities (e.g., Coexistence and AFWA)

$4: 45-5: 00$

Next Steps and Adjourn

Pat Field (CBI) 
Table A2. Workshop Participants

\begin{tabular}{|l|l|}
\hline Name & Organization \\
\hline Aaron Corcoran & University of Colorado-Colorado Springs \\
\hline Alicia Oller & Tetra Tech \\
\hline Amanda Hale & Texas Christian University \\
\hline Anupam Sharma & Iowa State University \\
\hline Bethany Straw & National Renewable Energy Laboratory \\
\hline Bob Thresher & National Renewable Energy Laboratory \\
\hline Brad Ring & U.S. Department of Energy \\
\hline Brad Romano & Invenergy \\
\hline Brogan Morton & NRG Systems \\
\hline Christi Calabrese & EDP Renewables \\
\hline Christian Newman & Electric Power Research Institute \\
\hline Christine Sutter & Natural Power \\
\hline Cris Hein & National Renewable Energy Laboratory \\
\hline Cyndi Edgely & National Renewable Energy Laboratory \\
\hline Danna Small & Pattern energy \\
\hline David Stoms & California Energy Commission \\
\hline Elise DeGeorge & National Renewable Energy Laboratory \\
\hline Galen Maclaurin & National Renewable Energy Laboratory \\
\hline Greg Aldrich & Duke Energy Renewables \\
\hline Isabel Gottlieb & Shoener Environmental \\
\hline Janine Crane & NextEra Energy Resources \\
\hline Jared Spence & General Electric Renewable Energy \\
\hline
\end{tabular}




\begin{tabular}{|l|l|}
\hline Name & Organization \\
\hline Jeff Eberling & Siemens Gamesa Renewable Energy \\
\hline Jen King & National Renewable Energy Laboratory \\
\hline Jennie Geiger & Apex Clean Energy Holdings \\
\hline Jenny McIvor & Berkshire Hathaway Energy \\
\hline Jocelyn Brown-Saracino & U.S. Department of Energy \\
\hline John Anderson & Edison Electric Institute \\
\hline Joy S Page & Defenders of Wildlife \\
\hline Kaj Skov Nielsen & Skov \\
\hline Karen Voltura & Colorado Parks and Wildlife \\
\hline Karin Sinclair & National Renewable Energy Laboratory \\
\hline Karyn Coppinger & General Electric Renewable Energy \\
\hline Kate Williams & Biodiversity Research Institute \\
\hline Laura Nagy & Avangrid Renewables \\
\hline Manuela Huso & U.S. Geological Survey \\
\hline Mark Hayes & Normandeau Associates, Inc. \\
\hline Martha Amador & U.S. Department of Energy \\
\hline Mary Hallisey & National Renewable Energy Laboratory \\
\hline Matthew Becker & Avangrid Renewables \\
\hline Michael Carella & U.S. Department of Energy \\
\hline Michael Lawson & National Renewable Energy Laboratory \\
\hline Michael Schirmacher & Bat Conservation International \\
\hline Michael Smotherman & Texas A\&M University \\
\hline Michael Speerschneider & American Wind Energy Association \\
\hline
\end{tabular}




\begin{tabular}{|l|l|}
\hline Name & Organization \\
\hline Michael Whitby & Bat Conservation International \\
\hline Mona Khalil & U.S. Geological Survey \\
\hline Nicholas Massey & U.S. Department of Energy \\
\hline Pasha Feinberg & Defenders of Wildlife \\
\hline Patrick Field & Consensus Building Institute \\
\hline Paul Cryan & U.S. Geological Survey \\
\hline Peter Sanzenbacher & U.S. Fish \& Wildlife Service \\
\hline Raphael Tisch & U.S. Department of Energy \\
\hline Rene Braud & Pattern Energy \\
\hline Rhett Good & Western EcoSystems Technology, Inc. \\
\hline Robert Carter & Mide' Technologies \\
\hline Ryan Luttrell & Boulder Imaging \\
\hline Sam Rooney & National Renewable Energy Laboratory \\
\hline Samantha Pounds & Kansas Department of Wildlife, Parks, and Tourism \\
\hline Sauro Liberatore & Mide' Technologies \\
\hline Scott Johnson & Siemens Gamesa Renewable Energy \\
\hline Scott Pruitt & U.S. Fish \& Wildlife Service \\
\hline Sean Marsan & U.S. Fish \& Wildlife Service \\
\hline Sherwood Snyder & Wildlife Acoustics Inc. \\
\hline Stephanie Horii & Consensus Building Institute \\
\hline Stu Webster & American Wind Wildlife Institute \\
\hline Taylor Parsons & DNV GL \\
\hline
\end{tabular}




\begin{tabular}{|l|l|}
\hline Name & Organization \\
\hline Terri Krantz & U.S. Department of Energy \\
\hline Tim Sichmeller & Western EcoSystems Technology, Inc. \\
\hline Tom Hiester & IdentiFlight International, LLC \\
\hline Trevor Peterson & Stantec \\
\hline Winifred Frick & Bat Conservation International \\
\hline
\end{tabular}




\section{Appendix B. Deterrent Breakout Groups and Facilitated Discussion \\ B.1Breakout Groups}

••Workshop participants divided into small, facilitated groups, with each group addressing two of four deterrent technology development and validation issues listed below:

1) Behavioral and Physiological Research Needs

2) Barriers and Challenges

3) Adapting Technologies

4) Novel Ideas

The following tables summarize major takeaways from notetakers and plenary report-outs. The content provided in the sections below are intended to reflect individual workshop participant input and do not represent consensus opinion nor recommendations of the National Renewable Energy Laboratory.

Table B1. Behavioral and Physiological Research Needs

\begin{tabular}{ll} 
Research Questions/Consideration \\
\hline
\end{tabular}$\quad \begin{array}{ll}\text { How do bats respond to ultrasound (jamming, annoyance, pain, etc.)? How and why do } \\
\text { bats shift their call frequencies? }\end{array}$




\section{Research Questions/Consideration}

What potential attracting factors can we retire (e.g., are bats attracted to the heat signature of wind turbines and if so, can the heat source be relocated). (i.e., can we attract bats away from the high-risk rotor swept area).

What are the tools used to monitor bats, what is their scale (e.g., acoustic detectors for turbine-scale, or radar for land-scape scale), and what questions can be answered with their use?

Can thermal videography be used to monitor wind turbines and airspace adjacent to wind turbines to assess how bats are moving within a wind energy facility.

Are potential attractants species-specific or habitat specific?

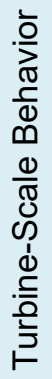

What is bat behavior like around other tall structures (e.g., trees, radio antenna, transmission poles, etc.)?

Where along the blades do collisions occur?

Do attractants override deterrent stimuli?

Do bats habituate to deterrent stimuli? If so, what is the timeframe?

Does insect abundance and availability at wind turbines correlate with bat activity and fatality?

Table B2. Barriers and Challenges

\section{Barrier/Challenge/Consideration}

What are the factors that impact the efficacy of deterrents (e.g., humidity, blade length, species present)?

\section{Solution Ideas (Brainstormed in} Small Groups)

Need deterrent technologies to be highly adaptable and robust, tailored to specific species and a wider range of species

Conduct early TRL testing and efficacy (e.g., test on the blade, different environmental conditions, etc.) through lab and ground-based studies on specific species and different signal patterns

Assess power draw from deterrent technologies, provide per-turbine estimates of installation, and projected maintenance/replacement costs

Work with researchers and statisticians to determine what would a robust study require (see Sinclair and DeGeorge 2016)
How to balance the need for a statistically robust experimental design with cost of monitoring? How can we optimize factors associated with obtaining a robust sample size (e.g., species-specific fatality, number of 


\section{Barrier/Challenge/Consideration}

\section{Solution Ideas (Brainstormed in}

Small Groups)

wind turbines, turbine size, equipment

failures).

How to quantify the ensonified airspace that elicits a deterrent response by bats?
Use 3D thermal videography and analysis software to track bats

Develop measuring methodology to quantify the ensonified area

Will bats habituate to deterrent stimuli? Need long-term datasets, could be done at ground level

What are options to monitor the performance of a technology?

Develop ability to remotely detect technical problems

Create an easily implementable back-up system

What are the options for sites that have incidental take permits to conduct research?

Provide for regulatory allowance for controlled experimentation

What criteria should be used to report results for comparability among research projects (e.g., use 95\% confidence intervals)?

Standardize reporting expectations and accepted statistical methods for studies and pilots done on new technologies

What mechanisms are available or could be created to increase the information exchange among regulatory entities (e.g., state guidelines or curtailment requirements)?

Encourage greater interstate coordination. Update the Wind Power Siting Regulations and Wildlife Guidelines in the United States (AFWA and USFWS 2007)

What are the incentives for developers/operators to validate technologies?

Reframe research as a positive (i.e., opportunity to potentially reduce regulatory burden)

Modify regulatory processes to allow greater flexibility (e.g., incorporate adaptive management) to test new technologies

How can we communicate economic considerations across projects to provide cost certainty for developers considering new projects?

Better disseminate economic factors from previous research studies that includes the cost associated with the technology, installation, and maintenance

How can we develop consistent funding mechanisms to maintain momentum in bat/wind research? For example, the DOE's seed money substantially jumpstarted deterrent research.
Develop a reliable mechanism for federal funding 
Barrier/Challenge/Consideration

How can we reduce monitoring costs associated with validating technology?

\section{Solution Ideas (Brainstormed in Small Groups)}

Pool resources to do a few good studies instead of repeating monitoring of limited value across many sites

Redirect monitoring costs at a site to direct conservation or learning measures

Create a level playing field - Request for Proposals (RFPs) could require or incentivize bids that include minimization strategies/technologies

Need strong coordination to foster cross-sector collaboration

the supply chain or ensure all relevant stakeholders are involved?

What fatality reduction is necessary to satisfy regulatory and conservation targets?

Need to develop fatality reduction targets, but an understanding of bat populations is necessary to put fatalities into context

What is the best way to frame the challenges and opportunities for conducting research and validating technologies

Positively frame research to resolve problems/exploring potential solutions

Table B3. Adapting Technologies

\section{Questions}

How can research and validating minimization strategies keep pace with the faster technological advances of wind turbines?

To what degree will attenuation/variation factors affect deterrent efficacy on taller turbines?

Consider combinations of monitoring techniques to fully assess the efficacy of deterrent technologies (e.g., pair thermal imaging with acoustics).

How often will a technology need to be maintained or replaced? What are the pros and cons of retrofitting existing turbines as opposed to including technologies as part of a package with new turbines?

How do costs compare across deterrent technologies (e.g., blade-mounted vs. nacellemounted? Include purchase, installation, operation, and maintenance costs.

Can we increase the deterrent intensity (e.g., making the acoustic deterrent louder)? Will this increase the power demand (and cost) to operate the deterrent.

Will taller wind turbines require a larger search radius? How much will that impact the cost of experimental studies? 


\section{Questions}

Will the deterrent cover the full rotor swept area (if needed)? If not, can the intensity of the signal be increased enough to address the issue? The higher frequency sounds (e.g., 50 $\mathrm{kHz}$ ) of ultrasonic deterrents likely cannot reach the ends of the longer blades at an intensity necessary to deter bats.

How does increasing blade lengths impact how bats interact with turbines and deterrent signals?

Will we need to pair nacelle-mounted deterrents with blade-mounted deterrents to ensure the entire rotor-swept area is ensonified?

What are the logistics of installing and maintaining blade-mounted deterrents?

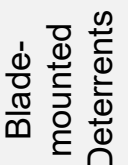

What efforts are being used to ensure the long-term reliability of blade-mounted deterrents?

What are the ideal locations along the blade for deterrents and how many are necessary?

What data are available on the effectiveness of using dim UV light?

Can we conduct an experimental study comparing ultrasonic deterrents with dim UV light?

How will dim UV lights work in different environments? What is the optimal placement for UV lights?

If effective, what is the process to scale up?

Can we conduct an experimental study pairing dim UV light with texture coating?



What are the next steps for passive acoustic deterrents? 
Table B4. Novel Ideas

\section{Ideas Generated by Small Groups}

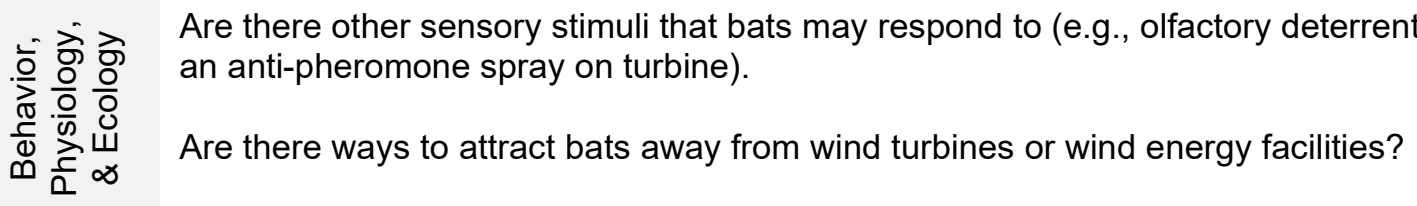

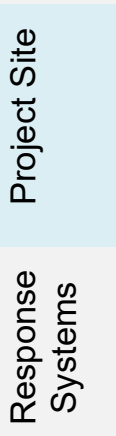

Is it possible to manipulate the habitat/surrounding landscape to reduce attraction to turbines (e.g., trees)?

Is it possible to install off-site, more "attractive" structures (e.g., bat mating poles that are taller than other turbines)?

With respect to monitoring behavior of bats in response to deterrent stimuli, how can we improve the analysis of thermal video observations? Can we use Artificial intelligence and machine learning to improve our analyses?

Develop open source/tools platform. Need experts to build code and make accessible to all researchers so average researchers can use.

Can we develop a more comprehensive regional approach to monitoring design, where near-ubiquitous low-level monitoring is paired with a smaller number of intense monitoring efforts? This will require immense collaboration and regulators agreeing to accept regional data rather than project-by-project), but this approach can help reduce monitoring costs overall and obtain truly comparable data. (Refer to BWEC 2018 workshop proceedings for additional discussion on this topic.)

Explore ways to address the following data sharing concerns: 1) Concern that the data will be used by wind opponents against new projects; 2) Concern about how the data will be used going forward, for example, by researchers that may "misuse" the data in biased investigations. 3) Lack of resources to compile/submit data after it is collected. Potential solutions may include:

1. Delay data submittal until a reasonable period after project construction

2. Establish scientific oversight for the use of collective industry data with equal representation from all stakeholders.

3. Include data compilation and submittals into SOW for consultants, explore opportunities to recover this cost through grants or other mechanisms, explore how to fund a data science intern program at AWEA and/or other organizations to process data for industry.

How can we improve study design and reduce costs of monitoring?

Are there funding mechanisms that leverage several sources? For example, can a couple of companies pool funding towards a more robust, regional study that benefits the overall industry and cost burdens do not fall on a select few companies. (Refer to BWEC 2018 workshop proceedings for additional discussion on this topic.)

Can incentives be created for "early adopters" to test new technologies/strategies, particularly needed help non-listed species conservation. This will require collaborating with regulatory agencies to develop an appropriate system that allows for experimentation 


\section{Ideas Generated by Small Groups}

while not adversely affecting wildlife (e.g., Candidate Conservation Agreements with Assurances).

Support $3^{\text {rd }}$-party testing or study validation to minimize bias.

\section{B.2Validating Deterrent Technologies Discussion Group}

Participants divided into two groups based on minimization strategy (i.e., deterrents or curtailment) to continue the discussion on research needs related to behavioral and physiological drivers, validating technologies and challenges with implementation. Key takeaways include:

\section{Understanding behavioral and physiological drivers}

- Assess behavioral and physiological mechanisms that drive bat activities, what stimuli override others (e.g., is the attractant more compelling than the deterrent), and distinguish differences across species.

- Collect additional information on what attracts bats to turbines. Build turbines in stages and monitor stages - does bat activity increase at a particular stage? Are bats attracted to similar tall structures such as communication towers?

- Investigate space beyond the rotor swept zone to better understand collision risk and exposure (is bat activity truly concentrated at turbines?).

- Use thermal videography and acoustic detectors to better understand bat behavior

- Develop new tools, such as small transmitters and radar to track bat movement patterns at different scales.

\section{Technology validation studies and analyses}

- Conduct studies focused on improving effectiveness of deterrents. For example, explore ways to increase ultrasonic stimuli or assess alternative sound patterns, such as short band clicks or frequency sweeps.

- Determine whether there are other sensory deterrents worth exploring.

- Understand the applicability of lab and ground-based field studies.

- Leverage machine learning capabilities to detect patterns.

- Determine the necessary level of monitoring to track long-term effectiveness (e.g., potential habituation). Consider supporting several sites across the US committed to do long-term studies.

\section{Implementation challenges and tracking efficacy}

- Determine species-specific variation in deterrent effectiveness. Are there within species differences (e.g., regional, between males and females or adults and juveniles).

- Establish mechanisms to share data to help efficiently improve technologies toward commercial deployment. 
- Encourage broader collaboration to leverage resources, apply for grants, and conduct more robust and meaningful study results.

- Explore ways to reduce monitoring cost. What are options to ensure that the investments for monitoring are worthwhile economically? 


\section{Appendix C. Curtailment Breakout Groups and Facilitated Discussion \\ C.1Breakout Groups}

Workshop participants divided into small, facilitated groups, with each group addressing two of four curtailment system technology development and validation issues:

1) Behavioral and Physiological Research Needs

2) Barriers and Challenges

3) Adapting Technologies

4) Novel Ideas

The following tables summarize major takeaways from notetakers and plenary report-outs. The content provided in the sections below are intended to reflect individual workshop participant input and do not represent consensus opinion nor recommendations of the National Renewable Energy Laboratory.

\section{Table C1. Behavioral and Physiological Research Needs}

\section{Research Question/Consideration}

In general, what are bats' sensory detection abilities and mechanisms for navigation (short and long distances), and what factors affect their sensory abilities (e.g., humidity)?

How do different weather conditions (wind speeds, barometric pressure, turbulence, and temperatures) influence species specific behavior?

How are bats processing and responding to different stimuli (e.g., sound, social calls, electromagnetic fields, etc.)?

How do different physiological conditions or states affect behavior (e.g., disease, prey abundance, hormones during mating season, pregnancy, etc.)?

What drives the pulses in seasonal bat mortality (large pulse in fall, small pulse in spring)?

Additional sensors advised (thermal video cameras) to detect bat species that are not always echolocating, and therefore, may not be captured by acoustic detectors.

What is the source of attraction? What conditions drive attraction and therefore increased collision risk? Can the attraction be mitigated by turbine operation?

What are the density and dispersal trends for each species across the year? Where are bats coming from and where are they going? Can migratory routes be defined? Need more

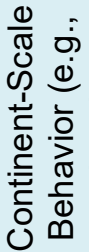
interstate coordination to understand population sizes and migratory pathways.

At what altitude do bats migrate? Explore bat movement from 3-D perspective (include elevation).

How do social cues influence behavior?

$\underset{\widetilde{d}}{\subset}$ \& At what altitude do bats move across the landscape? Explore bat movement from a 3-D

$\Xi$ 


\section{Research Question/Consideration}

How does bat activity vary across the landscape of a wind energy project (e.g., clustered around certain turbines or dispersed evenly across the landscape)? Are there commuting behaviors?

How do social cues influence behavior?

What is the source of attraction?

What are the conditions at the precise time of collision? Where did the collision occur on the turbine blade? Employ monitoring tools that is capable of documenting time of collision (thermal video).

Does survivorship vary depending on the nature of the turbine strike (e.g., will a bat that collides with the root side of the blade more likely survive than colliding with the blade tip)?

Both applied and fundamental research is needed.

Consider new technologies, such as from the medical field (smaller devices under the skin), tracking specific acoustics via drones

Can wildlife curtailment be synchronized with other curtailment needs? Explore timing curtailment with night bird migration. Not a major issue within the control of operators. Nonvoluntary curtailment must occur regardless of the grid or other curtailment.

Limited study season slows R\&D.

Table C2. Barriers and Challenges

\section{Barrier/Challenge/Consideration}

Challenging to demonstrate the magnitude of smart curtailment effectiveness and verify benefits compared to other minimization strategies.

\section{Possible Solutions}

Obtain baseline information through preconstruction monitoring above the ground to predict conditions where smart curtailment could work. Using thermal video is likely more practical than acoustic detectors due to poor pre-/postconstruction relationship.

Need higher resolution/ more accurate technology (with remote sensing ability) to track bat movements. Need more information on effective application (e.g., how many and where to deploy acoustic detectors across the facility property).

Develop machine learning tools to quickly identify bats.

Work with researchers and statisticians to determine what would a robust study require. 
See Sinclair and DeGeorge 2016 "Framework for testing the effectiveness of bat and eagle impact-reduction strategies at wind energy projects."

Need better equipment durability (e.g., acoustic monitoring devices susceptible to degradation) and ability to remotely monitor the equipment is functioning properly.
Work with OEM to integrate acoustic monitoring devices (or have option to install) into turbine design.

Improve durability/weatherization of equipment.
High uncertainty makes it difficult to identify the appropriate level of monitoring and defining "what is good enough."

Under what conditions might produce greater wildlife benefits if a portion of monitoring funds were reallocated from monitoring to other mitigation activities that directly benefit wildlife?
Modify regulatory processes that allow greater flexibility (e.g., improve adaptive management application) to overcome uncertainty barriers.

Identify acceptable conditions to reduce monitoring requirements and/or costs.

Explore opportunities to direct more efforts/resources to other activities such as conservation.

Large databases may help detect "data plateaus."

Conduct larger scale monitoring that reduces effort for individual facilities by dispersing monitoring across multiple facilities (e.g., random testing at a continental level). Use aggregated data to develop population dynamics models. All companies contribute into pooled funds to support this effort.

Develop incentives or processes to encourage greater transparency.

Lack of data sharing contributes to the high uncertainty problem.

Developers and financiers need certainty of costs defined at the beginning to judge whether the investment is worthwhile.

Unknown overall lifecycle costs, product durability, and productivity variability over time. Smart curtailment may not produce worthwhile costsavings (e.g., equipment, maintenance costs, etc., outweigh blanket curtailment costs).
Better disseminate information from studies and industry lessons learned.

Identify conditions where smart curtailment is more cost effective (e.g., possibly worthwhile when curtailing at 6-7 $\mathrm{m} / \mathrm{s}$ wind speeds, but cost-effectiveness compared to blanket curtailment may decrease with lower wind speeds). 


\section{Barrier/Challenge/Consideration}

\section{Possible Solutions}

Need to reduce monitoring costs overall.

Rigorous studies to meet regulatory demands are extremely expensive and complex. The long-term monitoring costs associated with incidental take permits are most cost prohibitive.
Pool resources to do a few good studies instead of repeating monitoring of limited value across many sites.

Redirect monitoring costs at a site to direct conservation or learning measures.

Consider incentives such as tax incentives.

Level the playing field - Request for proposals could require or incentivize bids that include wildlife minimization strategies/technologies.

Implementing a minimization strategy may place a company at a competitive disadvantage when bidding for projects.

"Free rider" concerns if others use the information from other companies' curtailment studies but do not contribute information themselves.

Government funding to conduct validation studies reduces cost burden on companies.

Foster cross-sector collaboration.

Many players along a complex supply chain.

Need strong program/project management leadership and coordination. 
Table C3. Adapting Technologies

\section{Adaptation Consideration}

Consider wind regime. Curtailing in a low-wind regime area may result in too great of a power loss for a project to be viable. Developers want to meet increasing customer demand; however suitable areas for expansion are limited. Explore different options for operations (e.g., not fully feather a turbine during curtailment to capture some energy production or weighting curtailment decisions based upon cost considerations).

Identify conditions and periods of risk by region, wind class, and frequency (not averages) (e.g., are the Appalachian mountains a region of high risk, or do frequency of low wind speeds create the risk?) to analyze potential power loss. For instance, period of risk in northeast is 2-3 months, southeast may have longer periods of risk due to different climate.

Identify which species are at risk at lower wind speed sites (new species of concern?), what conditions pose higher risk, and appropriate level of minimization strategies per species. Where are bats predominantly in the 3-D space?

Improve understanding of detailed flow features and atmospheric dynamics around the turbine. Measure wind speed at blade tips, not just on the nacelle. Model temperature-wind interaction effects on turbulence, turbine makes, and spacing.

Consider designs/systems that do not need to be reinvented for every new turbine design or site (e.g., universal SCADA integration across turbines).

Consider limitations of wind energy wildlife minimization in the context of other stressors. Determining how much to curtail for bats, particularly for endangered species, may prove too challenging as it implies the wind industry has more control over bat populations than in reality.

Consider potential relationship between turbine spacing and bat activity or fatality rates. What factors change with larger turbines and larger spacing? How close do bats need to be to the turbines to be at risk? Are fewer turbines (because larger size) leading to less mortality?

Consider limitations of how representative one turbine location can be of another. At what distance is one turbine location (and associated bat activity/fatality rates) no longer representative of what is happening at other turbines?

Consider developing a bat model that accounts for turbine size and spacing. The rotor-swept zone could be a variable. Utilize $10+$ years of data to explore this.

Consider monitoring needs. How will sample size be impacted? How much will plot sizes need to increase? Will more technology per turbine be necessary (e.g., will each turbine require acoustic monitors with more microphones aimed in different directions)? How will this influence costs of curtailment implementation and efficacy studies? Other landscape topography variables (e.g., forests, ponds, etc.) may make it more challenging to tease out turbine spacing impacts.

Consider relevance of previous analyses to current and future technological context. How applicable are past analyses to new technologies and facilities? Is there a need to redo some analyses?

Resolve hardware and software limitations (e.g., current software limits number of concurrent activities). Software is easier to modify; however, need to know what variables to program in at the start. 


\section{Adaptation Consideration}

Consider data transfer and remote-control needs.

Consider cybersecurity.

Leverage existing facilities to the fullest extent possible. What can be learned from existing facilities with additional instrumentation? Can these facilities serve as study sites to explore covariates that influence risk?

Table C4. Novel Ideas

\section{Ideas}

Is it possible to reduce rotor speeds such that bats see and navigate around turbines while still generating some power? (See Arnett et al. 2013b)

How does sheer influence bat behavior (e.g., flight altitude)?

Are there different and better ways of measuring bat activity/risk that could better refine curtailment?

Does it make sense to differentiate the settings based on species? Could we use different settings for foraging as opposed to migratory species?

Are collision risk higher after several days of bad foraging conditions?

(Will bats fly at higher wind speed after $3,4,5$, days of high wind or rain?)

Can combinations of minimization strategies (deterrents, off-site attractants, curtailment, conservation, etc.) offer improved efficacy and economic benefit?

Can wake steering to compensate for losses from individually curtailed turbines? E.g, consider curtailed turbines in real-time wake steering optimization.

What small tweaks with existing resources can be leveraged?

How can machine learning support response systems? Need abundant data and need to train with positive species identification.

What systems can identify high risk situation and species, then trigger the appropriate minimization strategy?

What level of standardized monitoring and reporting will best support accelerated solution development?

Can facilities work together to collectively reach reduction targets for non-listed species on a larger and more meaningful scale?

Can collision detection systems be employed to document precise time of collision?

What other technologies exist that help offset cost of curtailment (e.g., storage technology)?

How can more collaboration between bat biologists and turbine operators be encouraged/facilitated to creatively explore new possibilities and solutions? 


\section{Ideas}

What is the true cost of energy and true value of bats (in terms of ecosystem services and environmental economics)? Quantify to demonstrate benefits compared to conventional energy production.

What is an appropriate metric for evaluating mortality that translates well into business decisions? Consider different metrics such as bat/MW, bat/MW/hr, or cost/bat.

What incentives can be employed to encourage or reward "early adopters." Early adopters assume higher costs and risks when testing new technologies/strategies. This will require collaborating with regulatory agencies to develop an appropriate system that allows for experimentation while not adversely affecting wildlife. For example, explore mitigation framework for non-listed species similar to carbon trading or government subsidies for loss of energy production.

\section{C.2Validating Curtailment Systems Discussion Group}

Participants divided into two groups - deterrents and curtailment. Participants who engaged in the facilitated discussion on curtailment focused on additional studies on curtailment, identifying and quantifying risk/exposure to refine curtailment strategies, integrating other minimization strategies, and barriers to advance smart curtailment. Key takeaways from the discussion include:

\section{Next steps for blanket curtailment}

- Although participants broadly agree that blanket curtailment in general reduces bat fatalities, there is still a need to better understand different blanket curtailment strategies.

- Current information from curtailment studies seems fairly representative geographically.

- Blanket curtailment likely works for several bat species, but it may not for all species (especially endangered species). Studying blanket curtailment effectiveness for rare species may prove unfeasible or too costly to research.

- Most blanket curtailment studies focused on higher end of cut-in speeds $(6.5-6.9 \mathrm{~m} / \mathrm{s})$, whereas little information exists for lower speeds (less than $3.5 \mathrm{~m} / \mathrm{s}$ ) or incremental differences in cost/benefit for different cut-in speeds (e.g., is there a meaningful difference in risk reduction between 3.0 and $3.5 \mathrm{~m} / \mathrm{s}$ ?).

- Given that regulators currently prefer blanket curtailment in general, the industry would benefit from deeper understanding of the curtailment curve (i.e., shape of the curve regarding optimal wind speed to minimize power loss and bat fatalities) in the near term. For a long-term solution, the industry needs other strategies such as smart curtailment and deterrents.

- Consider evaluating how effective the AWEA best management practice (BMP) is that calls for feathering up to manufacture cut-in speeds. This BMP appears to be effective and result in low production losses. 


\section{Additional curtailment analyses}

- Need more studies to capture conditions of exposure risk (cannot obtain this from current fatality data) to estimate the risk reduction benefits for curtailment at different cut-in speeds. These estimates will be site-specific in the near term; eventually patterns should emerge as studies obtain more information.

- Additional studies should focus on areas with high uncertainty to help advance inference ability; additional studies in well-documented areas (e.g., Iowa) are less necessary.

- Expanding data sharing may bring to the surface existing information that can help address some of the curtailment uncertainties and reduce the need for more studies. Conversely, past studies may have limited application to inform future curtailment strategies given the major changes in technology, environmental conditions, etc.

- Explore different metrics to convey curtailment costs (e.g., use 'emissions if used fossil fuels for the same amount of energy' to convey environmental benefits or 'bat mortality per unit of KWh produced' to retain companies' pricing confidential).

- Consider methods to improve detection of bats in the rotor swept zone (acoustic detectors will not detect bats who are not echolocating). How important is this factor if reduction targets are met?

- Analyze differences between trigger system and conditions-based smart curtailment strategies. Dynamics of bat activity influence which approach may prove more effective. Conditions-based would have difficulty predicting sudden bursts of bat activity; trigger system may be less effective if steady stream of bats move through the system.

\section{Integrating deterrents into smart curtailment}

- Smart curtailment system could trigger deterrents (e.g., detects presence of bats, identifies species, and signals deterrents to emit frequency specific to that species) rather than having the deterrent constantly operating and emitting broadband frequencies.

- How can the regulatory framework support using these strategies? Can regulations/ requirements allow for industry to use any strategy(ies) to meet reduction targets or reduce monitoring requirements if the facility implements best available solution(s)?

\section{Implementation barriers}

- Implementing minimization strategies may place a company at a competitive disadvantage when bidding for projects. Need for "levelling the playing field" (e.g., requests for proposals require or incentivize bids that include minimization strategies/technologies), which may require regulatory modifications.

- Wind energy needs to be competitive with other energy options.

- Companies need to compensate in response to unexpected events (e.g., major storms) that decrease energy production, causing voluntary mitigation actions to become lower priority. 
- Curtailment strategies are site specific because of each facility's relatively unique conditions (e.g., wind speed, habitat, market, etc.) making it difficult to apply a fleet-wide strategy.

- Industry must comply with other wildlife mitigation requirements (e.g., eagles and other listed species). 